\title{
Evaluation of OFDM Channel Sounding Techniques with Three Modulation Sequences
}

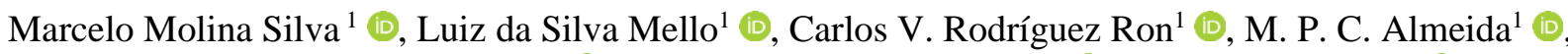 \\ Alexander B. Hilario Tacuri ${ }^{1}$ (D) Pedro Gonzalez Castellanos ${ }^{2}$ (D) L. H. Gonsioroski ${ }^{3}$ (B) \\ ${ }^{1}$ Pontifical Catholic University of Rio de Janeiro CETUC/PUC-Rio, Rio de Janeiro, Brazil \\ molina@cetuc.puc-rio.br, smello@cetuc.puc-rio.br, crodriguez@cetuc.puc-rio.br, \\ marta@cetuc.puc-rio.br,ahilario@cetuc.pu-rio.br, \\ ${ }^{2}$ Universidade Federal Fluminense da UFF, Rio de Janeiro, Brazil \\ psactellanos@id.uff.br \\ ${ }^{3}$ Universidade Estadual do Maranhão, Brazil \\ leonardo.gonsioroski@geticom.com
}

\begin{abstract}
This paper presents an evaluation of multicarrier channel sounding techniques using different random and pseudorandom sequences to modulate the OFDM sounding signal. The Random (Rand), Pseudo-Noise (PN) and Zadoff-Chu (ZC) were tested, both in laboratory simulations and in field measurements. For the laboratory simulations Matlab routines were used to generate OFDM signals modulated with each of the three sounding signals, that were then convoluted with a synthesized transfer function of a test channel with six multipath components and added Gaussian noise and Doppler fading. The resulting signals are then correlated with a copy of the original signal to provide the multipath power delay profiles. The root mean square deviation (RMSD) and the relationship between peak power and mean power (PAPR) were used as metrics for the comparison between the test transfer function and the simulation detected multipath delay profiles, showing slight advantages of the $\mathrm{ZC}$ sequence. The three sequences were then used in field measurements to characterize an urban channel at $700 \mathrm{MHz}$. In the field measurements, the $\mathrm{ZC}$ sequence showed the lowest detection threshold, allowing for the detection of a larger number of multipath components.
\end{abstract}

Index Terms - Broadband channel sounding, channel characterization, radio propagation.

\section{INTRODUCTION}

The rapid growth in the demand for broadband wireless communications in the last decade has driven the research on how to optimize the use of the electromagnetic spectrum, a limited resource shared with millions of users. The capacity of a wireless network depends fundamentally on the propagation channel behavior, that needs to be characterized.

In order to characterize the broadband wireless propagation channel at microwave and millimeter wave frequencies, different sounding techniques have been proposed and applied [1]-[6]. The transmission of narrow periodic pulse trains [1], the pulse compression technique [1]-[4] and the multicarrier OFDM transmission technique [5]-[6] are often used for the characterization of wideband 
Journal of Microwaves, Optoelectronics and Electromagnetic Applications, Vol. 18, No. 4, December 2019506 DOI: http://dx.doi.org/10.1590/2179-10742019v18i41704

channels in open areas. These techniques are used to obtain power delay profiles (PDP) of the channel, i.e., the power density at each relative time delay of the multipath components that reach the receiver at a given instant. The knowledge of the PDP allow the computation of the channel dispersion parameters, such as the average delay, the root mean square (r.m.s.) delay spread and the coherence bandwidth.

The multicarrier sounding technique consists of generating an OFDM signal that is modulated by a random or pseudo-random sequence and transmitted through the channel. At the receiver, the autocorrelation of the received signal generates correlation peaks that identify the multipath components. Usually, as the delay relative to the first component increases, the amplitudes of the components will decrease exponentially.

In this paper, the performance of the OFDM channel sounding technique is evaluated considering three different modulating sequences: a random sequence (Rand), a pseudo-noise sequence (PN) and a Zadoff-Chu sequence (ZC). The sequences were tested by a computer simulator using a deterministic channel transfer function representing, arbitrarily, six multipath components to which Gaussian noise was added as well as the Doppler effect. The synthesized OFDM modulated sequences are then convoluted with this channel transfer function to simulate the received signal. The autocorrelation of the received signal provides the channel PDP.

Besides the computer simulation, field measurements were performed at the central frequency of $773 \mathrm{MHz}$ and $20 \mathrm{MHz}$ bandwidth with a fixed transmitter and a mobile receiver. Experimental runs with each sequence were performed along the same, predefined route.

\section{MULTIPATH SOUNDING USING AN OFDM SIGNAL}

\section{A. Power Delay Profile}

The use of multicarrier OFDM signals for propagation channel sounding is described in detail [5][6]. As shown by Parsons [1], the time domain description of a channel can be obtained by expressing the autocorrelation function of the channel output in terms of the autocorrelation function of the delay scattering. For wide-sense stationary uncorrelated scattering (WSSUS) channels, the autocorrelation at the time of observation, can be simplified in the form

$$
R_{w}(t, t)=\int_{-\infty}^{+\infty}|z(t-\tau)|^{2} P_{h}(\tau) d \tau
$$

in which $P_{h}(\tau)$ is the channel PDP, i.e., the power density at relative time delays of the multipath components. If $|z(t)|^{2}$ is an impulse function then:

$$
R_{w}(t, t)=P_{h}(t)
$$

\section{B. Generation of the OFDM signal}

The OFDM signal is obtained as indicated in Fig. 1. Data bits are divided in multiple frames by a serial-parallel converter and each frame is digitally modulated. The IFFT (Inverse Fast Fourier 
Transform) block is responsible for modulating the orthogonal subcarriers with the complex symbols. After the IFFT process, a serial parallel converter will convert the discrete output samples into a temporal sequence representing the OFDM symbols. Finally, a cyclic prefix is added. To perform the sequences evaluation, the Rand, PN and ZC sequences were used as input in the Matlab simulation process shown in Fig 1.

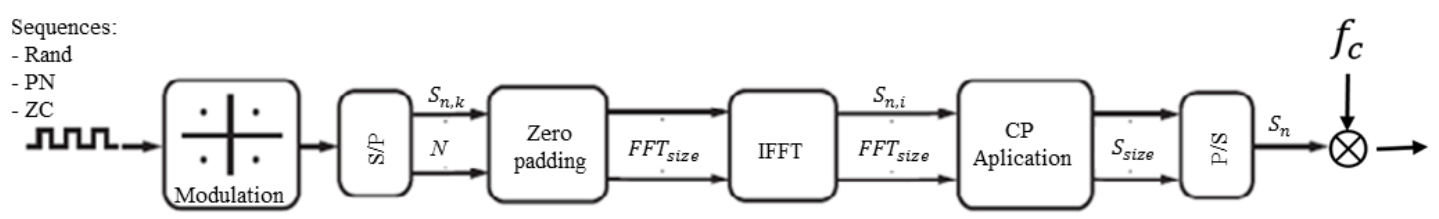

Fig. 1. OFDM signal generation [11].

\section{Random sequences tested}

The first sequence to be evaluated is the Rand sequence, formed by purely random bits $\left(a_{1}, \ldots, a_{n}\right)$ in which $a_{i}=\{0,1\}, i=0,1, \ldots, n$.

The second sequence is the PN sequence, discussed in [12]-[13]. It is a sequence of binary numbers which seems to be random, but is in fact deterministic. PN sequences are commonly used to generate noise that is approximately "white". Although it seems to have no definite pattern, PN consists of a deterministic sequence of pulses that will repeat over a long period. To construct a PN sequence of length $n=2^{m}-1$, a generating polynomial $\mathrm{h}(\mathrm{x})$, of degree $\mathrm{m}$, is used to specify a feedback displacement record. The most useful class of primitive polynomials is that of primitive trinomials, that are the simplest and the most efficient generators of random numbers. The original GFSR (generalized feedback shift register) generators were all based on primitive trinomials. As an example, for $\mathrm{m}=4$ let us consider the same primitive polynomial used in [11]:

$$
h(x)=x^{4}+x+1
$$

This polynomial specifies a feedback shift register consists of "m" blocks, which represent memory elements or flip-flops, each containing a registry 0 and 1 , as shown in fig 2.

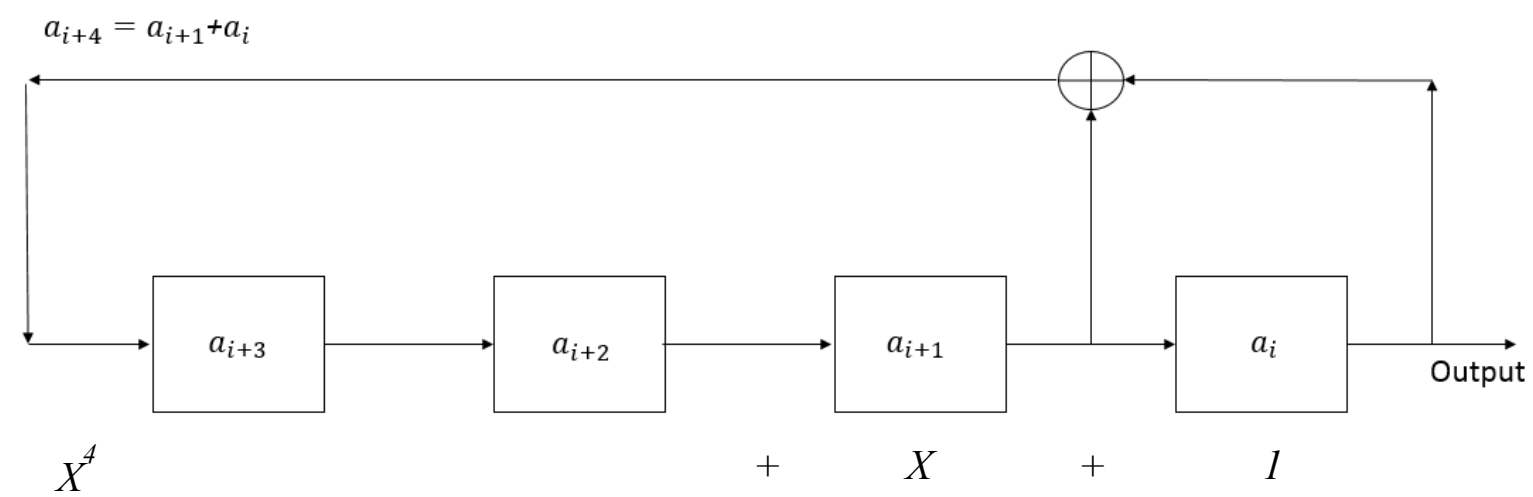

Fig. 2. Shift register for eq. (3). 
At each time unit the contents of the registers are shifted one position to the right, and the records corresponding to the terms of $\mathrm{h}(\mathrm{x})$ are summed and fed to the left registers. The sum $(+)$ represents an addition or exclusion port defined by $0+0=1+1=0$ and $0+1=1+0=1$.

In the example of Fig. 2, if at time $i$ the registers contain $a_{i+3}, a_{i+2}, a_{i+1}, a_{i}$, at time $i+1$ the registers will contain $a_{i+4}=a_{i+1}+a_{i}, a_{i+3}, a_{i+2}, a_{i+1}$. This feedback shift register generates an infinite sequence $a_{0}, a_{1}, \ldots, a_{i j} \ldots$ that satisfying the recurrence relation.

$$
a_{i+4}=a_{i+1}+a_{i} \quad i=0,1, \ldots y
$$

Each block contains 0 or 1 and there are $2^{m}$ possibilities for the shift register, so that the sequence $a_{0}, a_{1}, a_{2} \ldots$ must be periodic. As the sequence $0,0, \ldots 0$ cannot be used as a seed, or all the sequences will be composed of zeros, the maximum possible length is $2^{m}-1$.

The third sequence considered is the ZC sequence that, due to its better autocorrelation properties [14]-[16], is often used as a synchronization sequence in modern wireless systems replacing the conventional PN sequence. The ZC sequence is included in a class of polyphase sequences defined by

$$
X_{\mu}=\left\{x_{\mu}(n)=e^{-j \frac{\pi \mu n(n+1)}{N}}, n=0,1, \ldots, N-1\right\}
$$

in which $\mu \in\{1,2, \ldots, N-1\}$ is the root of the sequence and $\mathrm{N}$ is the number of samples, odd and prime. The $\mathrm{ZC}$ sequence has an ideal autocorrelation function (periodic autocorrelation is zero for all non-zero displacements).

\section{SimULATION OF THE MULTIPATH CHANNEL SOUNDING}

\section{A. Multipath Channel Simulation}

The OFDM signal is processed as indicated in Fig. 1, with a sampling frequency of $50 \mathrm{MHz}$, a 20 MHz bandwidth, an FFT size of 1024, a sampling factor of 2, and a cyclic prefix of 1/16 samples (128 samples).

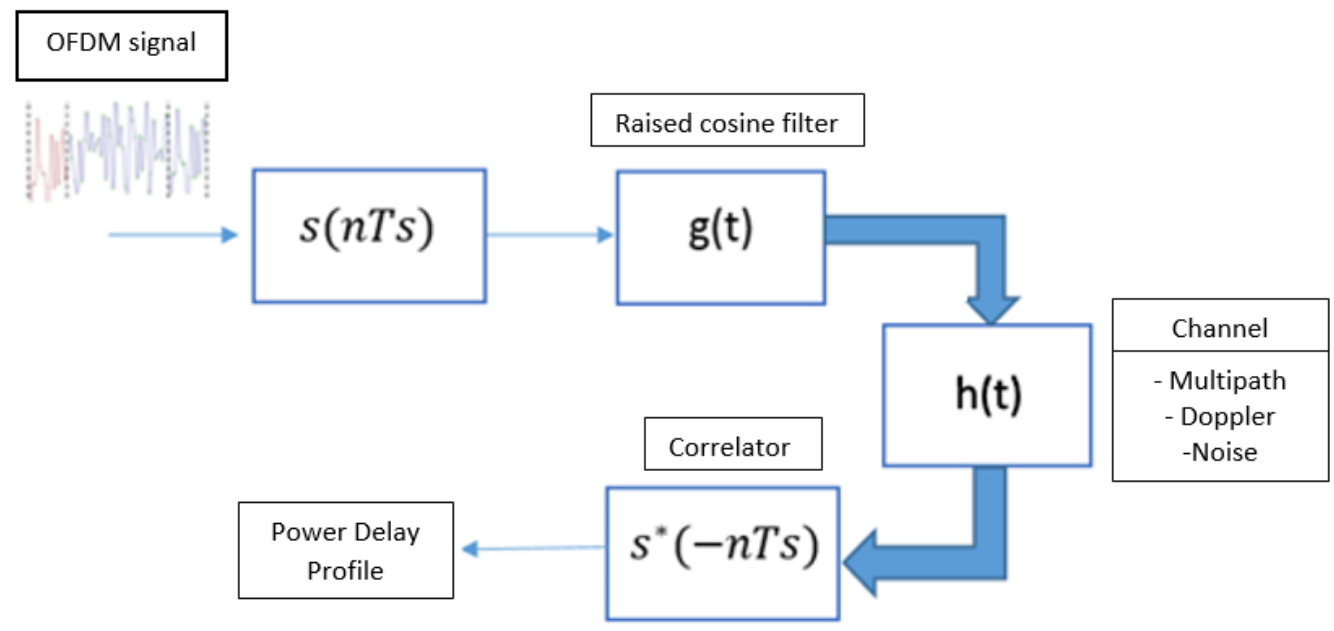

Fig. 3. Transmission and reception scheme for channel sounding. 
The OFDM signal is bandpass filtered by a raised cosine filter a bandwidth $B_{g}=30 \mathrm{MHz}$ to limit bandwidth and prevent aliasing.

The raised cosine filter transfer function is given by

$$
g(t)=\left[\frac{\operatorname{sen}\left(\pi t / T_{g}\right)}{\pi t / T_{g}}\right] \cdot\left[\frac{\cos \left(\pi t / T_{g}\right)}{1-\left(2 \alpha t / T_{g}\right)}\right]
$$

in which $T_{g}=1 /\left(B_{g}\right)$ and $\alpha \in[0,1]$ is the roll-off factor.

The filtered signal is then transmitted through the multipath channel represented by its impulsive response $h(t)$ that corresponds to $\mathrm{N}$ different paths each with a time delay and an attenuation. It is assumed that there is no correlation between the multipath components.

The simplest multipath channel model is the two-ray model, formed by a direct component and a reflected component. In this case, $h(t)$ can be expressed as:

$$
\begin{aligned}
& h(t)= {\left[a_{0} e^{j \Phi_{0}} e^{-j \omega \tau_{0}} \delta\left(t-\tau_{0}\right) \mathrm{D}_{0}+n_{0}\right]+\left[a_{1} e^{j \Phi_{1}-j \omega \tau_{1}} \delta\left(t-\tau_{1}\right) \mathrm{D}_{1}+n_{1}\right] } \\
& h(t)=a_{0} e^{j \Phi_{0}-j \omega \tau_{0}}\left[\left(\delta\left(t-\tau_{0}\right) \mathrm{D}_{0}+\frac{n_{0}}{a_{0} e^{j \Phi_{0}-j \omega \tau_{0}}}\right)\right. \\
&\left.+\left(\frac{a_{1}}{a_{0}} e^{j\left(\Phi_{1}-\Phi_{0}\right)} e^{-j \omega\left(\tau_{1}-\tau_{0}\right)} \delta\left(t-\tau_{1}\right) \mathrm{D}_{1}+\frac{n_{1}}{a_{0} e^{j \Phi_{0}-j \omega \tau_{0}}}\right)\right]
\end{aligned}
$$

in which

$-\tau_{i}$ is the delay of component $\mathrm{i}$.

$-a_{i}$ is the attenuation of component $i$.

- $\Phi_{i}$ is the phase change of component i.

$-D_{i}$ is the fading coefficient of component $\mathrm{i}$.

$-n_{i}$ is the noise of component $\mathrm{i}$.

This equation can be simplified by making $\tau_{0}=0, a_{1} / a_{0}=\alpha$ and $\Phi_{0}=0$.

$$
h(t)=a_{0}\left[\left(\delta(t) \mathrm{D}_{0}+\frac{n_{0}}{a_{0}}\right)+\left(\alpha e^{j \Phi_{1}} e^{-j \omega \tau_{1}} \delta\left(t-\tau_{1}\right) \mathrm{D}_{1}+\frac{n_{1}}{a_{0}}\right)\right]
$$

Applying the Fourier transform and considering that $F[\delta(t)]=1$ and $F\left[\delta\left(t-\tau_{1}\right)\right]=e^{-j 2 \pi \tau_{1} f_{\text {we have: }}}$

$$
H(f)=a_{0}\left[\left(\mathrm{D}_{0}+\frac{n_{0}}{a_{0}}\right)+\left(\alpha e^{j \Phi_{1}} e^{-j \omega \pi_{1}} e^{-j 2 \pi \pi_{1} f} \mathrm{D}_{1}+\frac{n_{1}}{a_{0}}\right)\right]
$$

A general channel transfer function with any number of multipaths can be obtained by adding delayed and attenuated components to equation (7). Each path in the multipath channel model is subject to independent fading [1]-[3]. For mobile communication, the receiver moves with a relative speed to the transmitter, resulting in Doppler effect with spectral power density represented by a Jakes 
spectrum [19]-[20]. In the simulation, a Doppler filter is applied to the signal samples in order to obtain the fading coefficients D.

\section{B. The Simulation Chain}

The filtering process is modeled by the convolution of the multipath channel and the raised cosine filter:

$$
g_{\text {sist }}(t)=h(t) * g(t)
$$

or, in the frequency domain

$$
G_{\text {sist }}(F)=H(f) \cdot G(F)
$$

Performing the simulation in Matlab requires that all data be discretized. The analog chain $G_{s y s t}(F)$ must be sampled at a suitable sampling frequency, $F_{S}=50 \mathrm{MHz}$.

$$
G_{\text {sist,samples }}\left(F / F_{S}\right)=F_{S} \sum_{-\infty}^{+\infty} G_{s y s}\left(F-k F_{S}\right)
$$

The entire system chain can now be modeled in the time domain as:

$$
x\left(n T_{S}\right)=s\left(n T_{s}\right) * g_{\text {sist } ; \text { samples }}\left(n T_{s}\right) * s^{*}\left(-n T_{s}\right)
$$

or, in the frequency domain,

$$
X(F)=S(F) \cdot G_{\text {sist,samples }}(F) \cdot S^{*}(F)
$$

The $x\left(n T_{\varsigma}\right)$ samples are the correlator outputs, which can be used to generate the power delay profile [16].

\section{Simulation Results}

For the performance evaluation of the three OFDM signals, modulated by Rand, PN and ZC sequences, a synthetized channel was created with six multipaths (delayed and attenuated) using the Matlab programming tool. The effects of noise and Doppler were included. Several simulation runs were carried out in order to evaluate which of the three sounding signals best characterizes the channel.

Fig 4 shows the multipaths detected in the channel sounding, with the three sequences, for a SNR of $10 \mathrm{~dB}$. The black curve in the figure, representing the channel, is the result of the convolution of the multipath channel transfer function with the raised cosine filter function, as indicated in equation (11).

Fig 5 shows the effect of the environment on the propagating signal. The multipath channel response is represented by the black line and the channel with Doppler effect is represented by the blue line. Fig 6 shows the results of the root mean square deviation (RMSD) with the three different 
Journal of Microwaves, Optoelectronics and Electromagnetic Applications, Vol. 18, No. 4, December 2019511 DOI: http://dx.doi.org/10.1590/2179-10742019v18i41704

sequences. The RMSD values are presented in Table I.

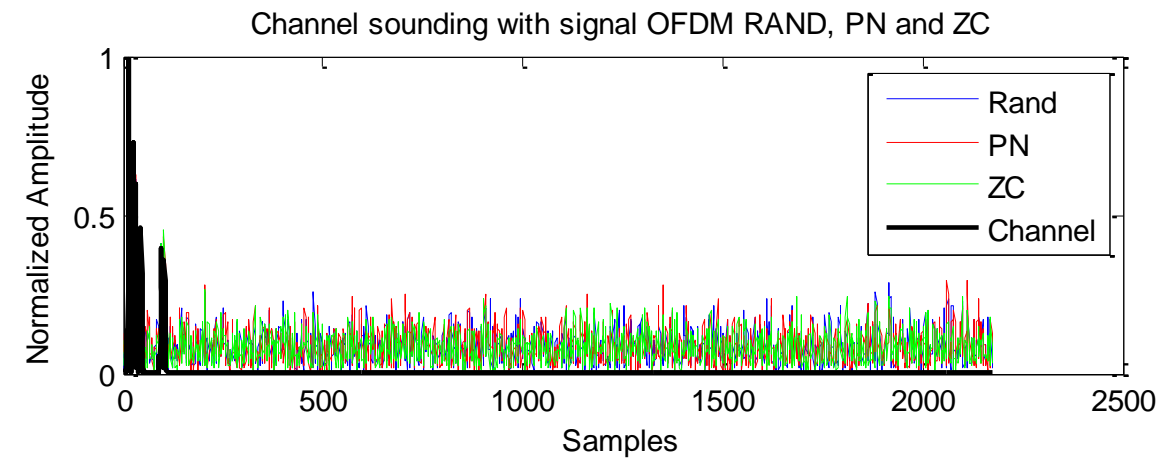

Channel sounding with signal OFDM RAND, PN and ZC

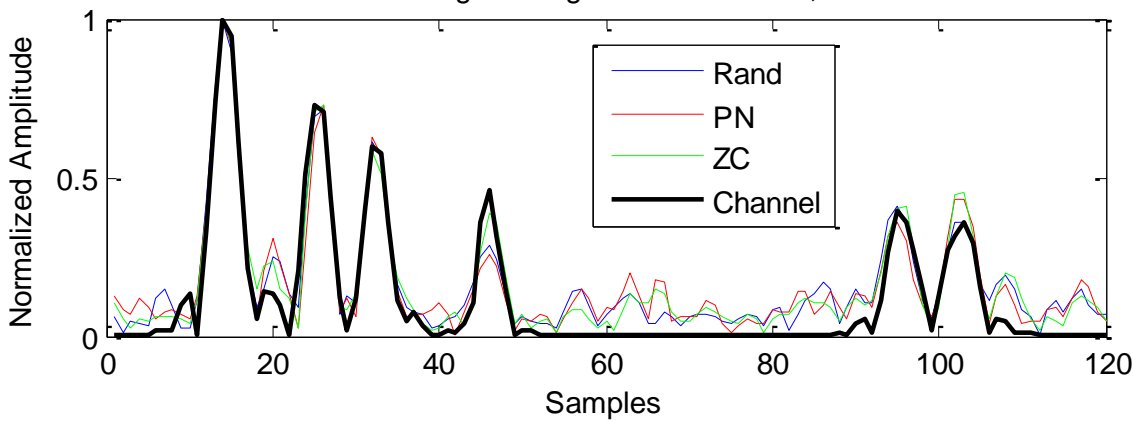

Fig. 4. Channel sounding with OFDM signals modulated Rand, PN and ZC with sequences.

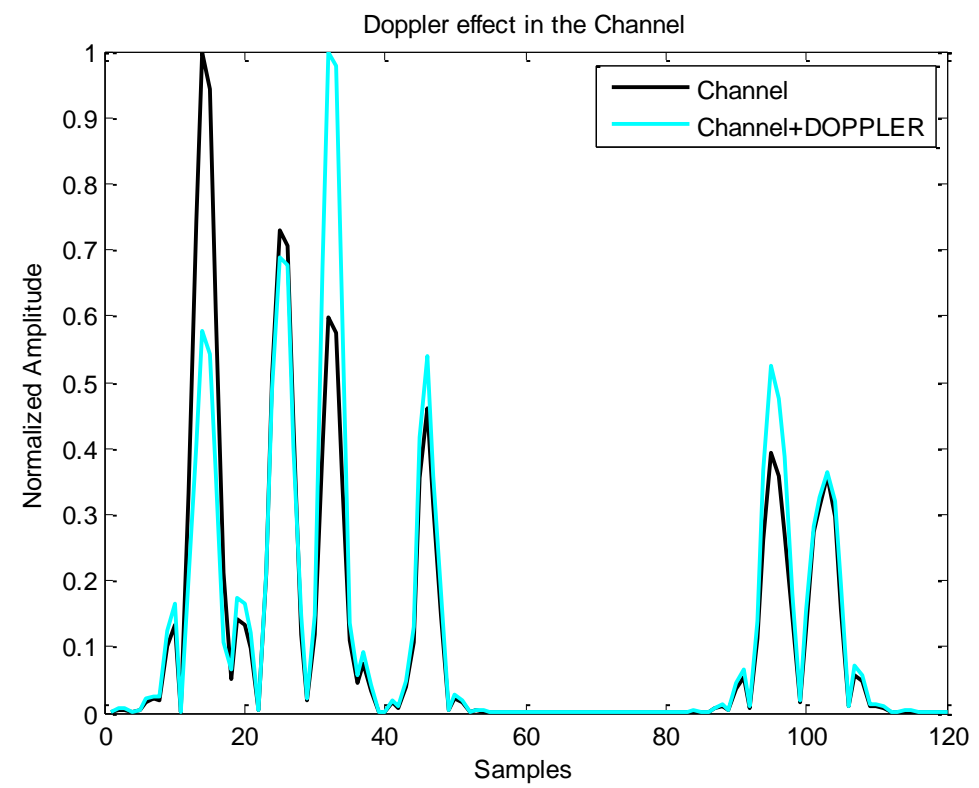

Fig 5. The Doppler effect on the channel components. 
Journal of Microwaves, Optoelectronics and Electromagnetic Applications, Vol. 18, No. 4, December 2019512 DOI: http://dx.doi.org/10.1590/2179-10742019v18i41704
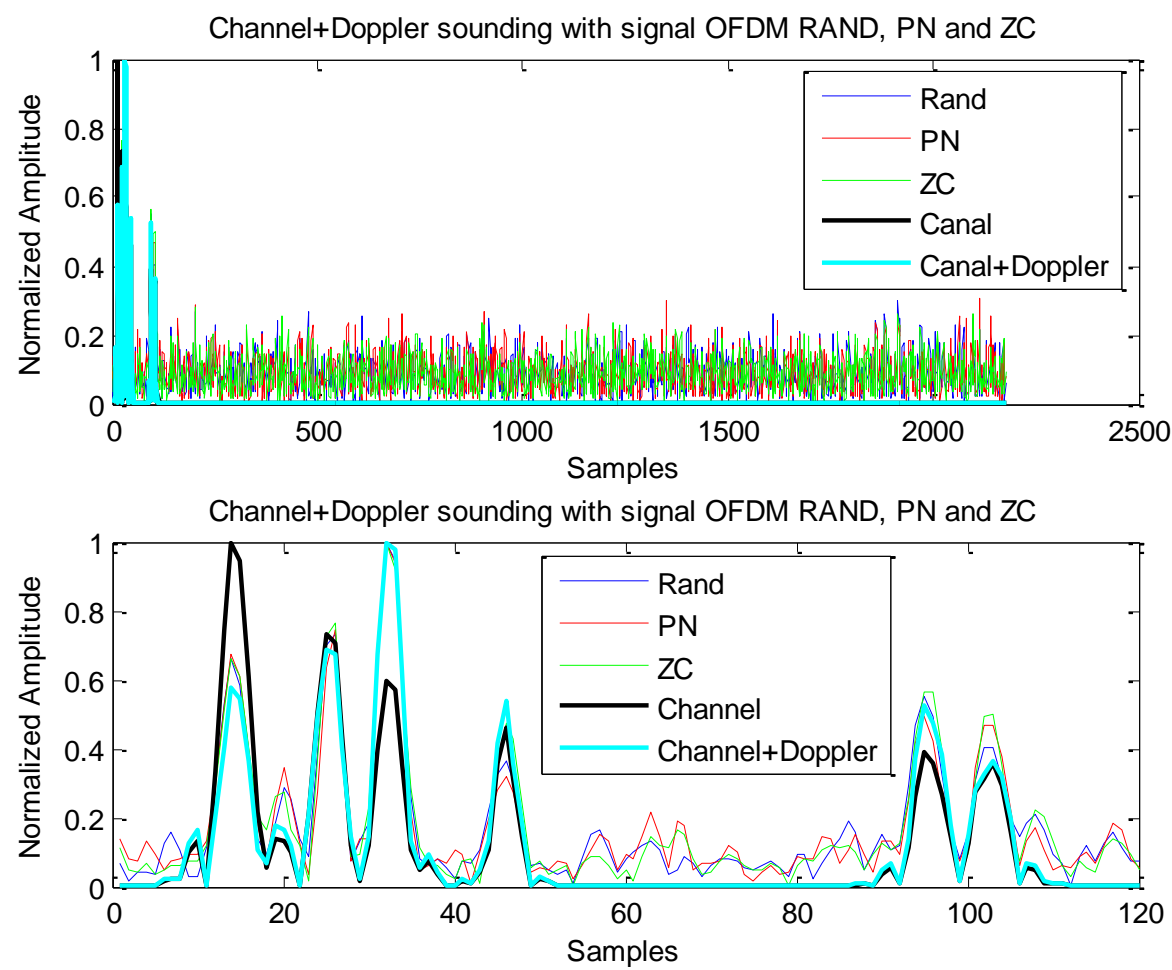

Fig. 6. Channel sounding plus Doppler effect with OFDM signals with sequences: Rand, PN and ZC.

\section{A. Sounding errors}

The performance of the sounding sequences was evaluated by the RMSD, given by equation (16). The results for a SNR of $10 \mathrm{~dB}$ are presented in Table I.

$$
\text { RMSD }=\sqrt{\frac{\sum_{i=1}^{n}\left(\hat{x}_{i}-x_{i}\right)^{2}}{n}}
$$

TABLE I: ROOT MEAN SQUARE DEVIATION (RMDS) ERROR FOR SNR = 10 DB.

\begin{tabular}{|c|c|c|}
\hline SNR 10 dB & Channel + Noise & Channel + Noise + Doppler \\
\hline Rand & 0.078 & 0.085 \\
\hline PN & 0.088 & 0.094 \\
\hline ZC & 0.073 & 0.082 \\
\hline
\end{tabular}

To verify the influence of noise, Fig 7 shows the RMSD with signal-to-noise ratios from $-10 \mathrm{~dB}$ to 10 $\mathrm{dB}$. The higher the signal to noise ratio, the lower the RMSD. It can be observed that the ZC sequence provides smaller RMSD values when compared to the Rand and PN sequences. 


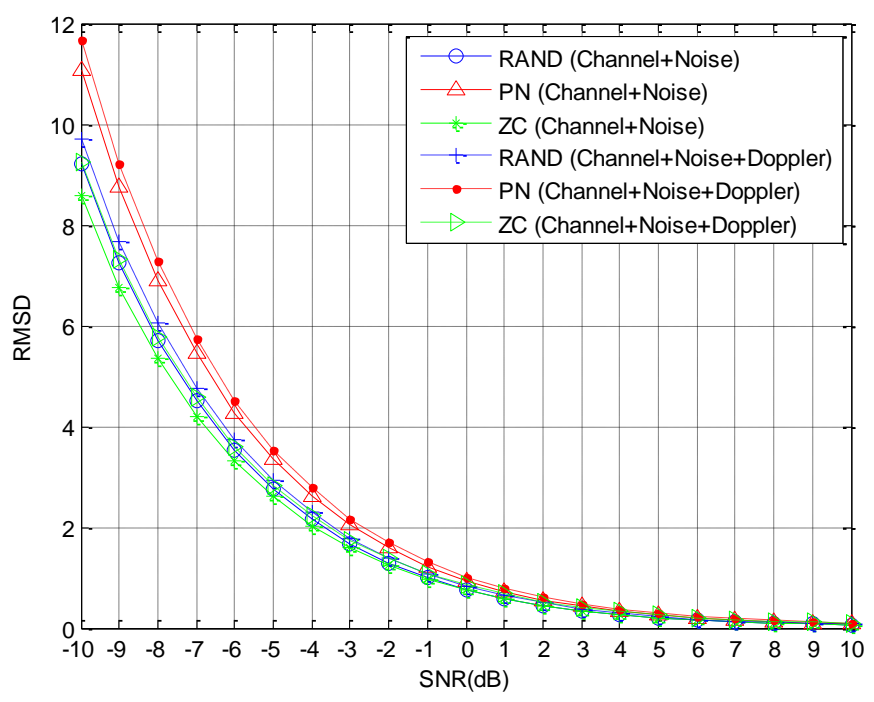

Fig 7. Channel sounding with SNR: -10 to $10 \mathrm{~dB}$, obtaining RMSD.

\section{B. Sounding fluctuations}

The sounding fluctuations correspond to the variations of the channel sounding results in the sections where there is no multipath. The evaluation of these noisy components is important due to the fact that, in some cases, these variations can be wrongly interpreted as multipath components, as exemplified in Fig 8, where sample 160 shows is a strong noisy component which can be interpreted as a multipath.

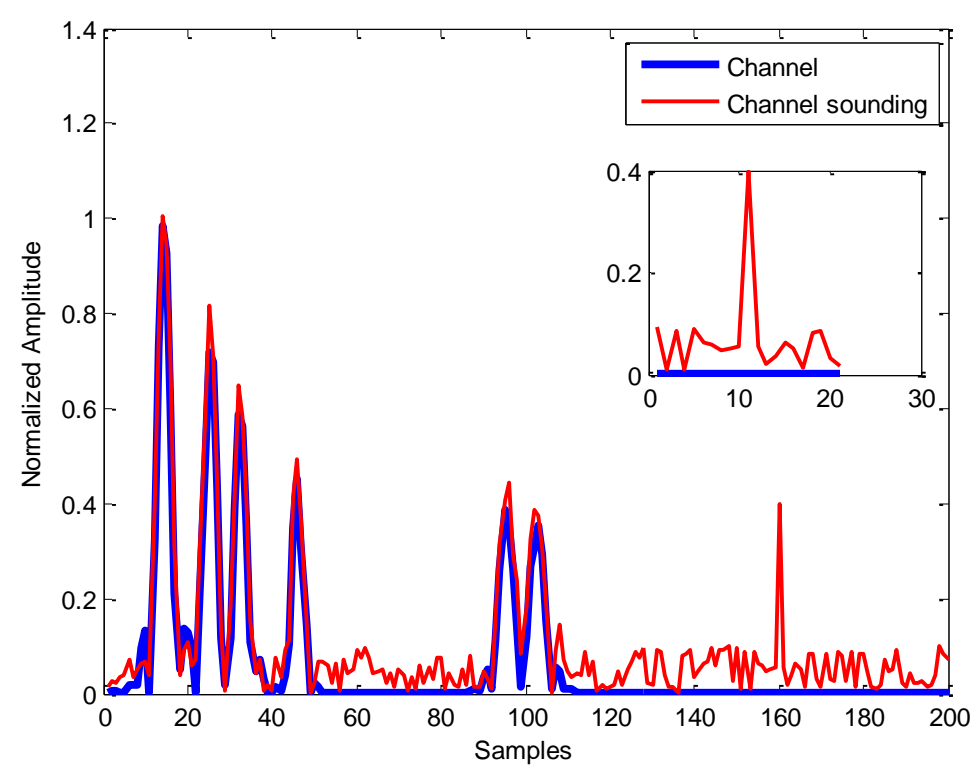

Fig 8. Sounding to the channel created.

In the simulation, the six multipath components are located in the first 128 samples. When the channel sounding is performed, fluctuations are generated by the autocorrelation process that depend on the sounding sequence spectrum. An example of these fluctuations is shown in Fig 9 for the three different sequences. The RMSD results of the fluctuations shown in Fig. 9 are presented in Table 2. 
Journal of Microwaves, Optoelectronics and Electromagnetic Applications, Vol. 18, No. 4, December 2019514 DOI: http://dx.doi.org/10.1590/2179-10742019v18i41704

The sounding signal that produces the least variations with respect to the actual channel will be more suitable for the sounding. It is possible to observe in table II that the OFDM signal with the sounding sequence ZC produces less fluctuation than the other signals using the RAND and PN sequences.
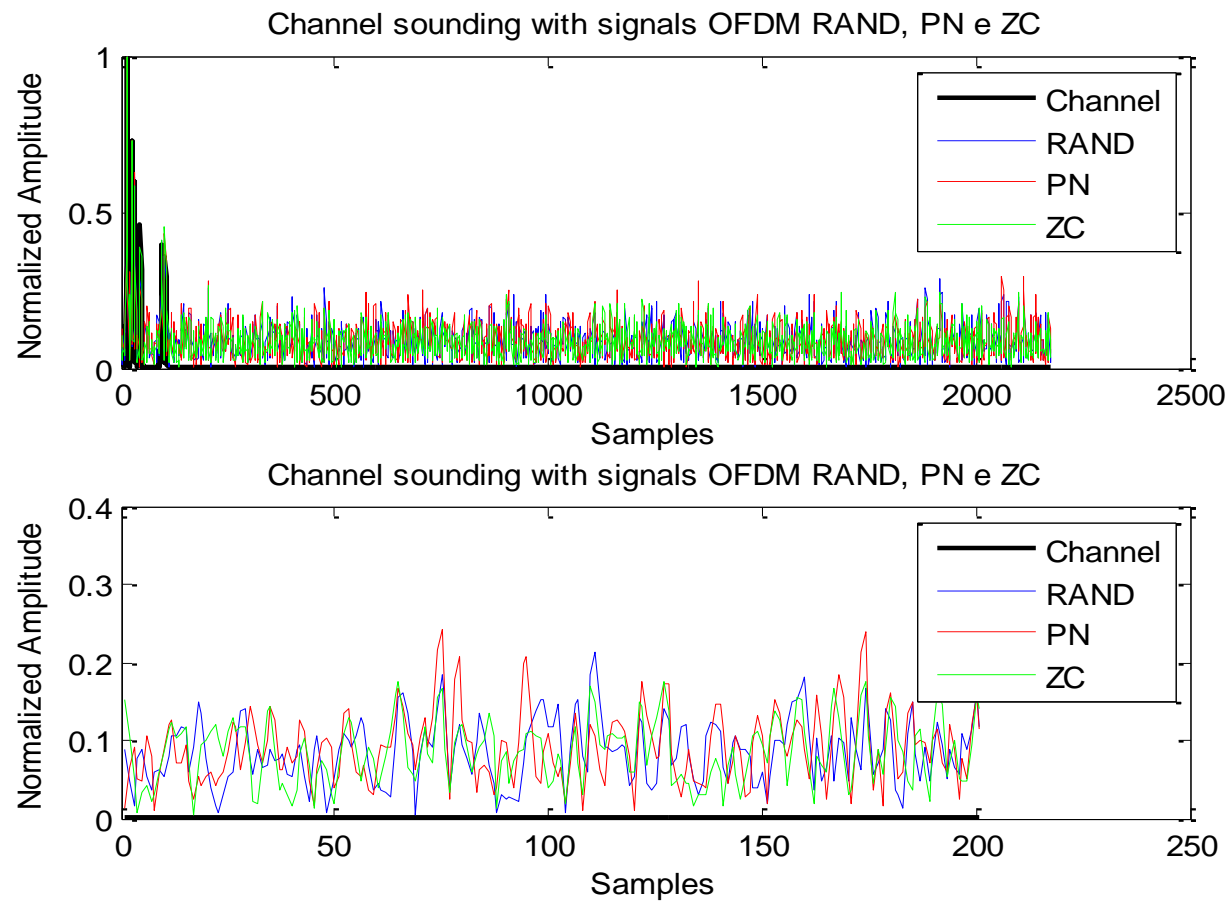

Fig. 9. Fluctuations in channel sounding.

TABLE II. RMSD OF SOUNDING FLUCTUATIONS

\begin{tabular}{|c|c|c|}
\hline & CANAL+RUIDO & CANAL+RUIDO+DOPPLER \\
\hline Rand & 0.099 & 0.105 \\
\hline PN & 0.102 & 0.107 \\
\hline ZC & 0.097 & 0.104 \\
\hline
\end{tabular}

\section{Peak power ratio and mean power (PAPR)}

Another important parameter that should be considered in the evaluation of the sequences is the ratio between the peak power and the mean power of the transmitted OFDM signal. Due to the large number of independently modulated subcarriers in an OFDM system, the peak power value can be very high as compared to the average power. High peak-to-average power ratio (PAPR) leads to inband distortion and out-of-band spurious due to the non-linearity of the high-power amplifiers [21] and can be a drawback in OFDM systems.

$$
\text { PAPR }=\frac{P_{p p}}{P_{p m}}=\frac{\max \left(|s(t)|^{2}\right)}{\frac{1}{T_{s}} \int_{0}^{T_{s}}|s(t)|^{2} d t}
$$


Journal of Microwaves, Optoelectronics and Electromagnetic Applications, Vol. 18, No. 4, December 2019515 DOI: http://dx.doi.org/10.1590/2179-10742019v18i41704

$$
\text { PAPR }=\frac{\max \left(\|\left. s(t)\right|^{2}\right)}{E\left(|s(t)|^{2}\right)}, \quad 0<t<T_{s}
$$

Using the "CCDF Graf Monitor" tool of the "IQ producer" MatLab routine, the relation between the peak power and the average power can be obtained. The results obtained for the probability distributions of PAPR for each sequence are shown in Fig 10. The ZC (green color) provided the lowest relations between peak power and average power.

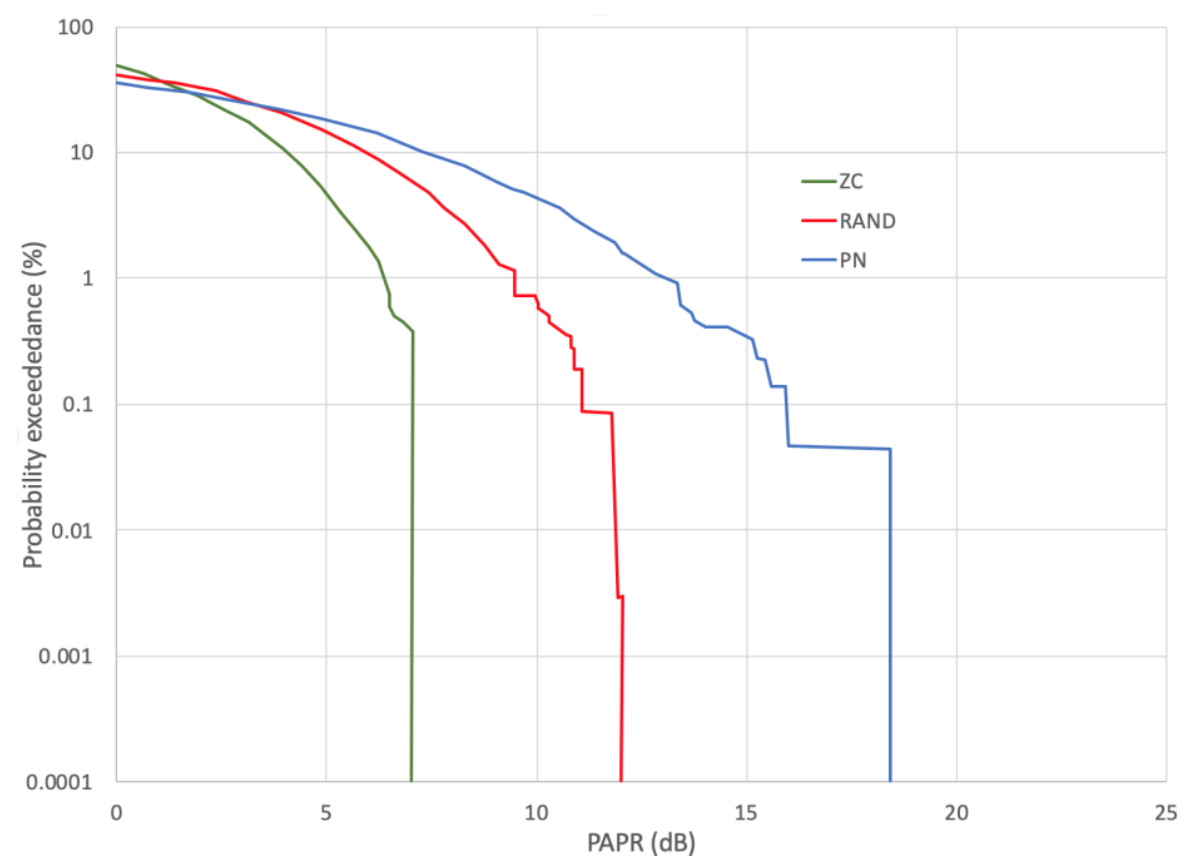

Fig. 10. Power Peak / Average Power probability distributions.

\section{Conclusions on the sounding simulations}

The results presented above show that the ZC sequence provides slightly smaller sounding errors and fluctuations and a smaller peak to average power ratio than the RAND and PN sequences. The differences, however, are not enough to indicate definite advantages of the use of this sequence in computer simulations. However, as it will be shown next, that is not the case when the sounding is performed in field measurements.

\section{MEASUREMEnTS CAMPAign}

After performing the laboratory simulations evaluation, the Rand, PN and ZC sequences were used in field measurements to characterize a $20 \mathrm{MHz}$ bandwidth broadband channel with central frequency of $773 \mathrm{MHz}$.

\section{A. Measurements setup}

The OFDM sounding signal modulated by each sequence was generated as discussed in section II, using the parameters shown in Table III. The transmission and reception equipment's are shown in Fig 11 and the transmitter and receiver parameters are given in Tables V and VI. 
Journal of Microwaves, Optoelectronics and Electromagnetic Applications, Vol. 18, No. 4, December 2019516 DOI: http://dx.doi.org/10.1590/2179-10742019v18i41704

TABLE III. SOUNDING SIGNAL PARAMETERS

\begin{tabular}{|c|c|}
\hline Signal Band $\left(B_{s}\right) \mathrm{MHz}$ & 20 \\
\hline Band of the signal of use $\left(B_{\text {su }}\right) \mathrm{MHz}$ & 19.53 \\
\hline Frequency sampling $\left(F_{s}\right) \mathrm{MHz}$ & 25 \\
\hline Sampling factor & 2 \\
\hline FFT Size - NFFT & 2048 \\
\hline Spacing between subcarriers $\Delta f_{s} \mathrm{kHz}$ & 9.765 \\
\hline Time of use $\left(T_{B}\right) \mu \mathrm{s}$ & 40.96 \\
\hline "Cyclic prefix relation (CP) samples & $1 / 1 / 16$ \\
\hline Guard time $\left(T_{g}\right) \mu \mathrm{s}$ & 2.56 \\
\hline OFDM symbol time $\left(T_{S}\right) \mu \mathrm{s}$ & 43.52 \\
\hline Number of sub-carriers in use $\left(N_{\text {used }}\right)$ & 800 \\
\hline Guard subcarriers $N_{\text {gward,left }}$ and $N_{\text {gward,right }}$ & 128 \\
\hline " Doppler resolution $\mathrm{kHz}$ & 11.5 \\
\hline "Multipath Resolution $\mathrm{m}$ & 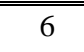 \\
\hline
\end{tabular}

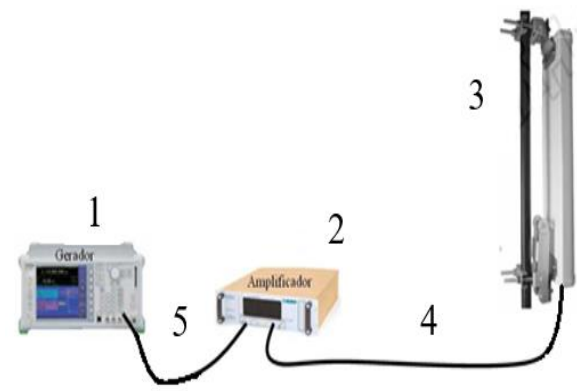

(a)

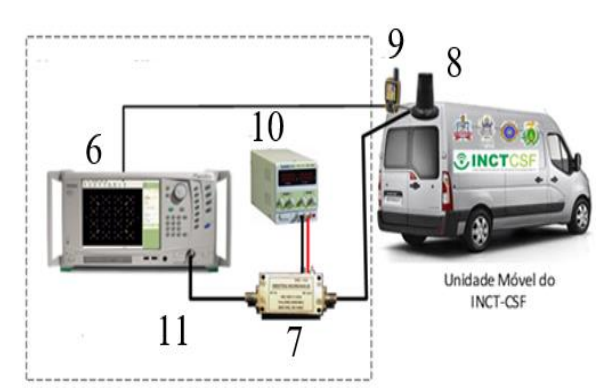

(b)

Fig. 11. Equipment used for measurements: (a) Transmission (b) Reception.

TABLE IV. EQUIPMENT USED FOR TRANSMISSION AND RECEPTION

\begin{tabular}{|c|c|c|c|}
\hline \multicolumn{2}{|r|}{ Transmission } & & \\
\hline Num & Equipments & Model & Observations \\
\hline 1 & Signal Generator & MG3700A, Anritu & $250 \mathrm{kHz}-6 \mathrm{GHz}$ \\
\hline 2 & RF Amplifier & Empower 500 & $500-2500 \mathrm{MHz}$ \\
\hline 3 & Sectorial Antenna & LNX-6512DS-TOM & $698-896 \mathrm{MHz}$ \\
\hline 4 & Wire & L4A-PNMNM-3M & $3 \mathrm{~m}, 0.6 \mathrm{~dB}$ attenuation \\
\hline 5 & Wire & 141-24NM+, MiniCirc. & $60 \mathrm{~cm}, 0.3 \mathrm{~dB}$ attenuation \\
\hline \multicolumn{2}{|r|}{ Reception } & & \\
\hline Num & Equipments & Model & Observations \\
\hline 6 & Signal analyzer & MS2692A, Anritu & $125-6000 \mathrm{MHz}$ \\
\hline 7 & LNA & ZX60-83LN-S+Mini & $500-8000 \mathrm{MHz}$ \\
\hline 8 & Omni Antenna & MGRM-WLF Series & $694-894 \mathrm{MHz} \& 1.7-2.7 \mathrm{GHz}$ \\
\hline 9 & GPS & GPSMAP 60CSx & Displacement record \\
\hline 10 & DC Regulated Source & MPL-1305M, Minipa & $0-32 \mathrm{~V}$ \\
\hline 11 & Wire & RG142 & $30 \mathrm{~cm}, \mathrm{~N}(\mathrm{M})-\mathrm{SMA}$, Atte. $1.4 \mathrm{~dB}$ \\
\hline
\end{tabular}


Journal of Microwaves, Optoelectronics and Electromagnetic Applications, Vol. 18, No. 4, December 2019517 DOI: http://dx.doi.org/10.1590/2179-10742019v18i41704

TABLE V. PARAMETERS - TRANSMISSION

\begin{tabular}{|c|c|}
\hline Parameter & Value \\
\hline Signal Generator Power & $-16 \mathrm{dBm}$ \\
\hline Transmission Frequency & $773 \mathrm{MHz}$ \\
\hline Power Amplifier Gain & $48 \mathrm{~dB}$ \\
\hline Transmit Antenna Gain & $14 \mathrm{dBi}$ \\
\hline Wire and connectors losses & $3 \mathrm{~dB}$ \\
\hline EiRP & $\mathbf{4 3 ~ d B m}$ \\
\hline
\end{tabular}

TABLE VI. PARAMETERS - RECEPTION

\begin{tabular}{|c|c|}
\hline Parameter & Value \\
\hline Reception Antenna Gain & $3 \mathrm{dBi}$ \\
\hline Wire and connectors losses & $3 \mathrm{~dB}$ \\
\hline Gain on the Low Noise Amplifier (LNA) & $21 \mathrm{~dB}$ \\
\hline Receiver antenna height & $3 \mathrm{~m}$ \\
\hline
\end{tabular}

The antenna and transmission equipment were installed 45 meters above the ground, on the twelfth floor of a building in the PUC-Rio University campus, as shown in Fig. 12 (a). For the reception, a mobile laboratory was used, shown in Fig. 12 (b).
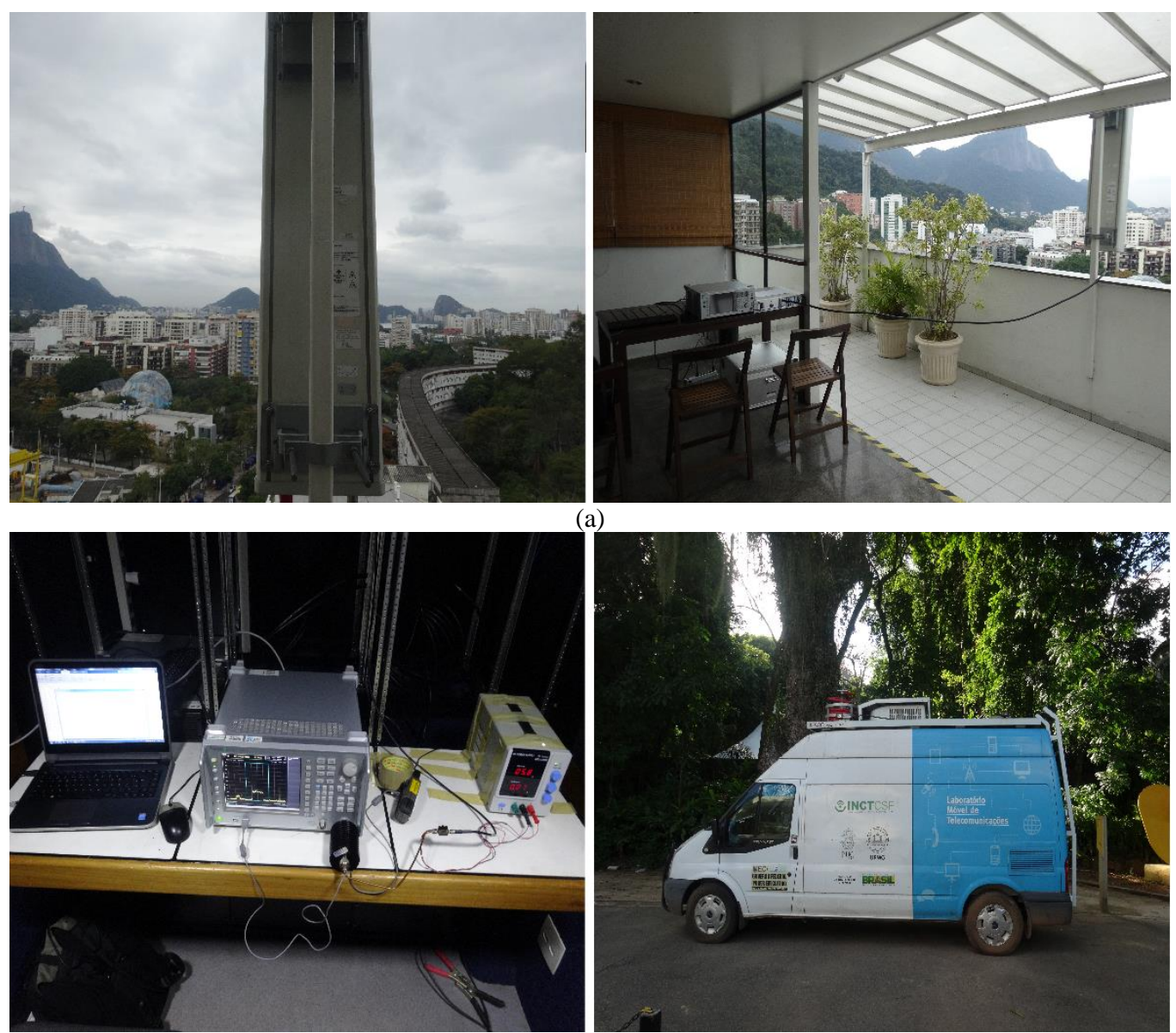

(b)

Fig. 12. Measurement setup: (a) transmission (b) reception.

Brazilian Microwave and Optoelectronics Society-SBMO Brazilian Society of Electromagnetism-SBMag received 1 Apr 2019; for review 4 Apr 2019; accepted 19 Sept 2019 (c) 2019 SBMO/SBMag (cc) BY 
Journal of Microwaves, Optoelectronics and Electromagnetic Applications, Vol. 18, No. 4, December 2019518 DOI: http://dx.doi.org/10.1590/2179-10742019v18i41704

\section{B. Channel characterization}

In order to characterize the broadband channel, the measured path delay profiles were analyzed to provide:

- the average delay and RMS delay spread;

- the cumulative probability distributions of:

- the RMS delays of the multipath components;

- the number of multipath components;

- the amplitudes of multipath components.

The empirical distributions were then fitted by theoretical probability distributions to characterize the statistical behavior of the channel parameters.

The constant false alarm rate filtering technique (CFAR) [17]-[18] was used, in order to avoid that undesired spurious be falsely interpreted as multipath. This technique was initially developed for radar systems to avoid erroneous detection due to channel noise, and currently is the most used filtering technique in channel sounding. The CFAR algorithm requires that a PDP peak be present in three consecutive sounding samples to be considered a valid multipath component. It also defines a noise threshold for each individual profile based on the calculation of the median power and the standard deviation from the PDP. This filtering procedure is of paramount importance for the calculation of channel dispersion parameters.

\section{Average Delay and RMS Delay Spread}

Experimental runs along the same route were performed to characterize the channel with each sounding signal. The measurements route, in the Gavea and Leblon neighborhoods of urban Rio de Janeiro, is shown in Fig 13.

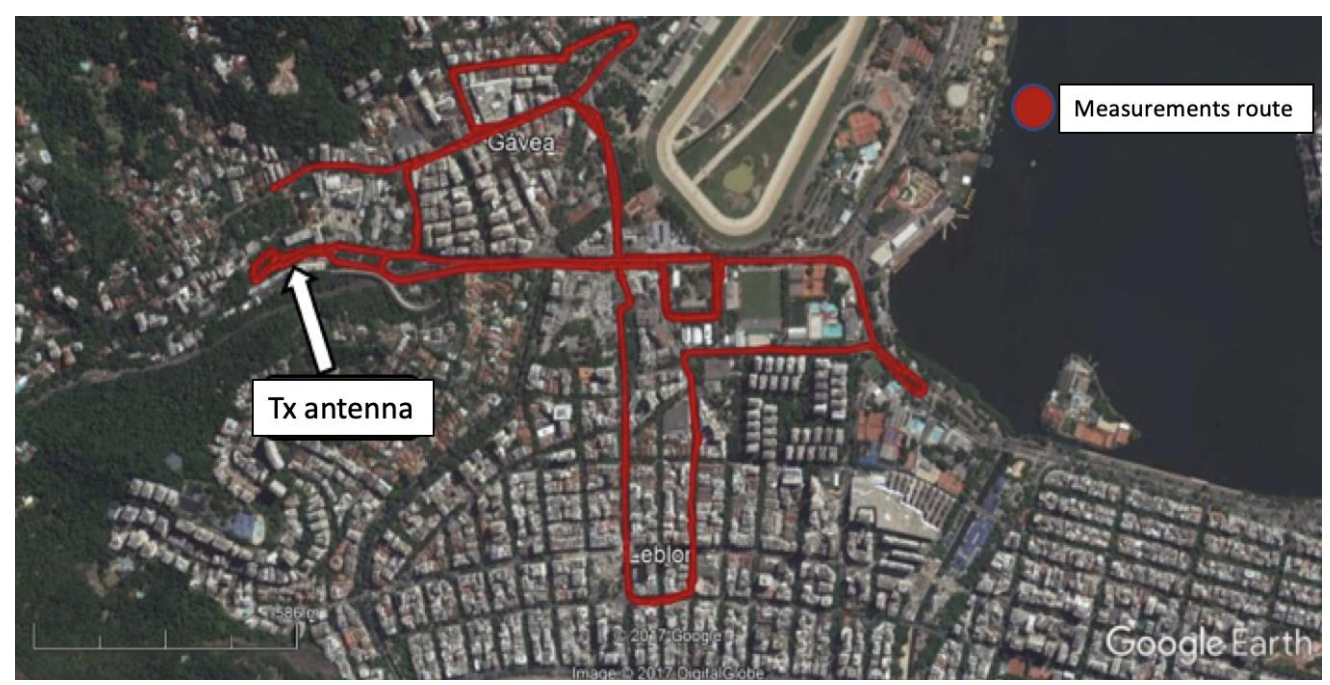

Fig. 13. Measurements route

Due to the traffic conditions, a different number of profiles may be acquired in each run. To ensure a better comparison, the route was divided in 10 meters segments and mean values of the mean delay and RMS delay spread were averaged for each section to allow the evaluation of the sounding Brazilian Microwave and Optoelectronics Society-SBMO received 1 Apr 2019; for review 4 Apr 2019; accepted 19 Sept 2019 Brazilian Society of Electromagnetism-SBMag 
Journal of Microwaves, Optoelectronics and Electromagnetic Applications, Vol. 18, No. 4, December 2019519 DOI: http://dx.doi.org/10.1590/2179-10742019v18i41704

sequences under the same conditions. Table VII shows the mean values and standard deviation of the average delay and the RMS delay spread considering all route segments.

TABLE VII. AVERAGE DELAY AND RMS DELAY OBTAINED FROM THE COMMON FACTOR AND THE SEGMENTATION

\begin{tabular}{|c|c|c|c|c|}
\hline \multirow{2}{*}{ Sequences } & \multicolumn{2}{|c|}{ Average Delay $(\boldsymbol{\mu} \boldsymbol{s})$} & \multicolumn{2}{c|}{ RMS Delay Spread $(\boldsymbol{\mu} \boldsymbol{s})$} \\
\cline { 2 - 5 } & Mean & $\begin{array}{c}\text { Standard } \\
\text { Deviation }\end{array}$ & Mean & Standard Deviation \\
\hline RAND & 0.21 & 0.083 & 0.13 & 0.065 \\
\hline PN & 0.16 & 0.058 & 0.08 & 0057 \\
\hline ZC & 0.22 & 0.060 & 0.18 & 0,069 \\
\hline
\end{tabular}

The cumulative distributions of the RMS delay spread were also obtained and are shown in Fig 14. These distributions were then fitted with the Lognormal, Gaussian, Weibull, Nakagami, Rice and Rayleigh probability distributions. The parameters of the theoretical distributions were determined by maximum likelihood estimates (MLE), with a 95\% confidence interval. The results are depicted in Fig 15 and the fitted parameters shown in Table VIII.

The results for the RMS Delay Spread shown in Table VII indicate that the ZC sequence shows greater dispersion. The same can be observed in Fig. 14, where the sequence ZC, represented by the green line, shows larger delays than the other two distributions.

The Rayleigh distribution provides the best fit to the distribution of the measurements obtained with the Rand sequence. For the case of the PN sequence measurements, the best fit is obtained with the Lognormal distribution, whereas in the case of ZC measurements the Gaussian distribution was the closest fit to the empirical results.

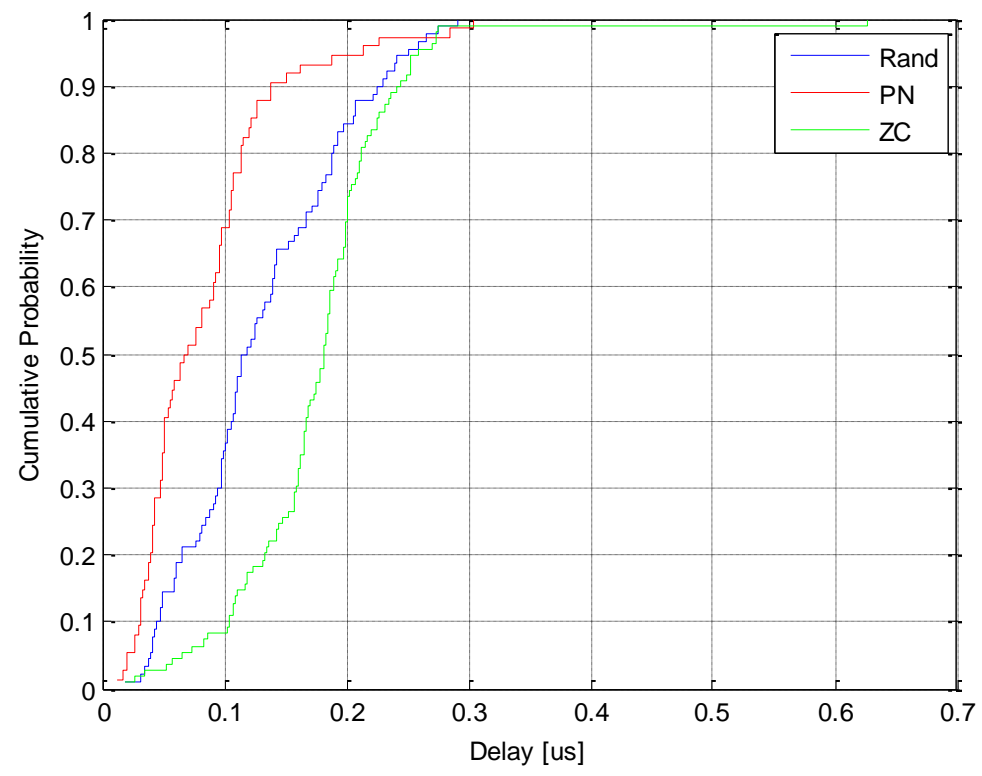

Fig. 14. Cumulative Distributions of measured RMS Delay Spread: Rand, PN and ZC 
Journal of Microwaves, Optoelectronics and Electromagnetic Applications, Vol. 18, No. 4, December 2019520 DOI: http://dx.doi.org/10.1590/2179-10742019v18i41704

TABLE VIII. FITTED PARAMETERS OF RMS DELAY SPREAD CUMULATIVE DISTRIBUTIONS

\begin{tabular}{|c|c|c|c|c|c|c|c|c|c|c|c|}
\hline \multirow{2}{*}{$\begin{array}{c}\text { RAND } \\
\text { Sequence }\end{array}$} & \multicolumn{2}{|c|}{ LogNormal } & \multicolumn{2}{|c|}{ Gaussian } & \multicolumn{2}{|c|}{ Weibull } & \multicolumn{2}{|c|}{ Nakagami } & \multicolumn{2}{|c|}{ Rice } & \multirow{2}{*}{$\begin{array}{c}\text { Rayleigh } \\
\sigma\end{array}$} \\
\hline & $\mu$ & $\sigma$ & $\mu$ & $\sigma$ & $\mu$ & $\sigma$ & $\mu$ & $\sigma$ & $\mu$ & $\sigma$ & \\
\hline $\begin{array}{c}\text { MLE } \\
\text { estimated } \\
\text { parameters }\end{array}$ & -2.20 & 0.59 & 0.13 & 0.07 & 0.15 & 2.11 & 1,09 & 0,02 & 0,08 & 0,09 & 0,10 \\
\hline $\begin{array}{c}\begin{array}{c}\text { Mean of } \\
\text { error }\end{array} \\
\end{array}$ & \multicolumn{2}{|c|}{0.006} & \multicolumn{2}{|c|}{-0.004} & \multicolumn{2}{|c|}{0.0001} & \multicolumn{2}{|c|}{0.001} & \multicolumn{2}{|c|}{0.001} & 0.0053 \\
\hline RMS error & \multicolumn{2}{|c|}{0.039} & \multicolumn{2}{|c|}{0.034} & \multicolumn{2}{|c|}{0.022} & \multicolumn{2}{|c|}{0.021} & \multicolumn{2}{|c|}{0.021} & 0.020 \\
\hline \multirow{2}{*}{ PN Sequence } & \multicolumn{2}{|c|}{ LogNormal } & \multicolumn{2}{|c|}{ Gaussian } & \multicolumn{2}{|c|}{ Weibull } & \multicolumn{2}{|c|}{ Nakagami } & \multicolumn{2}{|c|}{ Rice } & Rayleigh \\
\hline & $\boldsymbol{\mu}$ & $\sigma$ & $\mu$ & $\sigma$ & $\mu$ & $\sigma$ & $\mu$ & $\sigma$ & $\mu$ & $\sigma$ & $\sigma$ \\
\hline $\begin{array}{c}\text { MLE } \\
\text { estimated } \\
\text { parameters }\end{array}$ & -2.71 & 0.663 & 0.082 & 0.057 & 0.092 & 1.579 & 0,737 & 0,010 & 0,003 & 0,071 & 0,071 \\
\hline $\begin{array}{c}\text { Mean of } \\
\text { error }\end{array}$ & \multicolumn{2}{|c|}{0.001} & \multicolumn{2}{|c|}{-0.009} & \multicolumn{2}{|c|}{-0.003} & \multicolumn{2}{|c|}{-0.010} & \multicolumn{2}{|c|}{-0.022} & -0.022 \\
\hline RMS error & \multicolumn{2}{|c|}{0.025} & \multicolumn{2}{|c|}{0.057} & \multicolumn{2}{|c|}{0.033} & \multicolumn{2}{|c|}{0.042} & \multicolumn{2}{|c|}{0.061} & 0.061 \\
\hline \multirow{2}{*}{ ZC Sequence } & \multicolumn{2}{|c|}{ LogNormal } & \multicolumn{2}{|c|}{ Gaussian } & Wei & pull & Nak & gami & Ric & & Rayleigh \\
\hline & $\mu$ & $\sigma$ & $\mu$ & $\sigma$ & $\mu$ & $\sigma$ & $\mu$ & $\sigma$ & $\mu$ & $\sigma$ & $\sigma$ \\
\hline $\begin{array}{c}\text { MLE } \\
\text { estimated } \\
\text { parameters }\end{array}$ & -1.82 & 0.464 & 0.176 & 0.069 & 0.197 & 2.497 & 1,741 & 0,036 & 0,0001 & 0,134 & 0,134 \\
\hline $\begin{array}{c}\begin{array}{c}\text { Mean of } \\
\text { error }\end{array} \\
\end{array}$ & & 006 & -0.0 & 05 & 0.0 & & & 001 & 0.0 & & 0.014 \\
\hline RMS error & & 64 & & & 0.0 & & & 43 & $0.0^{\circ}$ & & 0.079 \\
\hline
\end{tabular}

Table IX shows the values of RMS delay spread exceeded for $50 \%$ and $95 \%$ of the cases. It can be observed that the ZC sequence is able to identify longer delays. These values are considered in systems design, as the coherence bandwidth is inversely proportional to the RMS delay spread. For channel bandwidths larger than the coherence bandwidth the received signal can suffer significant intersymbol interference.

All the evaluations were performed in a $2.5 \mu$ s time window using the first 125 sounding samples, as the $\mathrm{ZC}$ sequence shows correlation peaks outside this range. Each peak generates a replica of the channel and in data processing these replicas can be interpreted by multipath clusters [19]. This is the main limitation of the use of the ZC sequence. On the other hand, within the range of $2.5 \mu$ s, the ZC sequence is able to identify a larger number of multipath components. Fig 16 shows an example of delay profiles captured at one point, after the CFAR filtering 
Journal of Microwaves, Optoelectronics and Electromagnetic Applications, Vol. 18, No. 4, December 2019521 DOI: http://dx.doi.org/10.1590/2179-10742019v18i41704

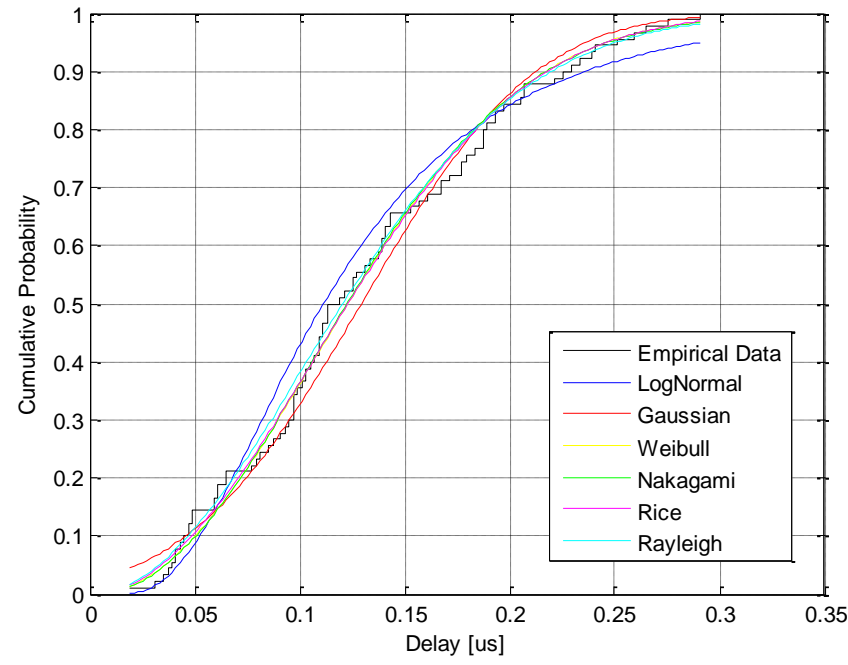

(a)

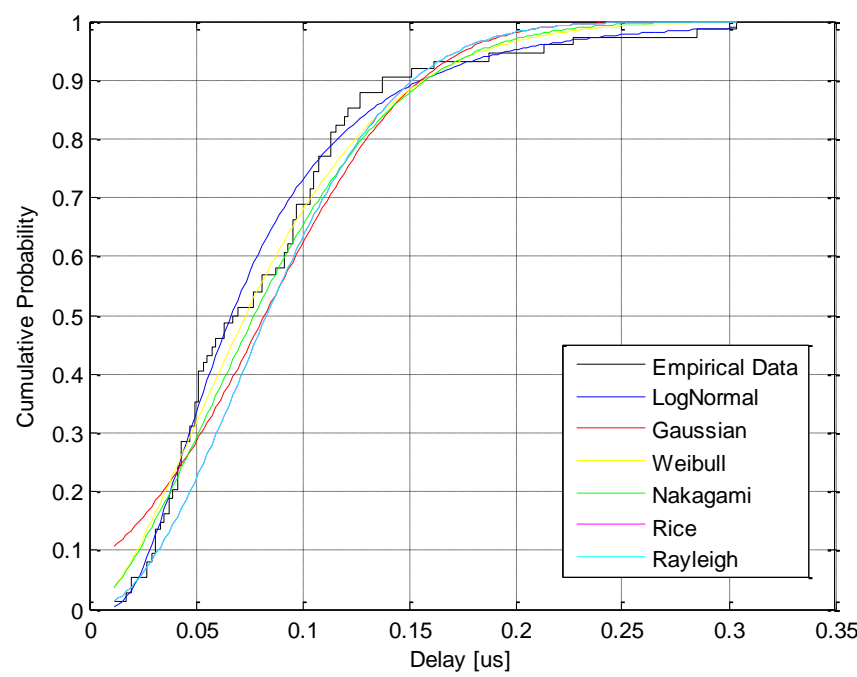

(b)

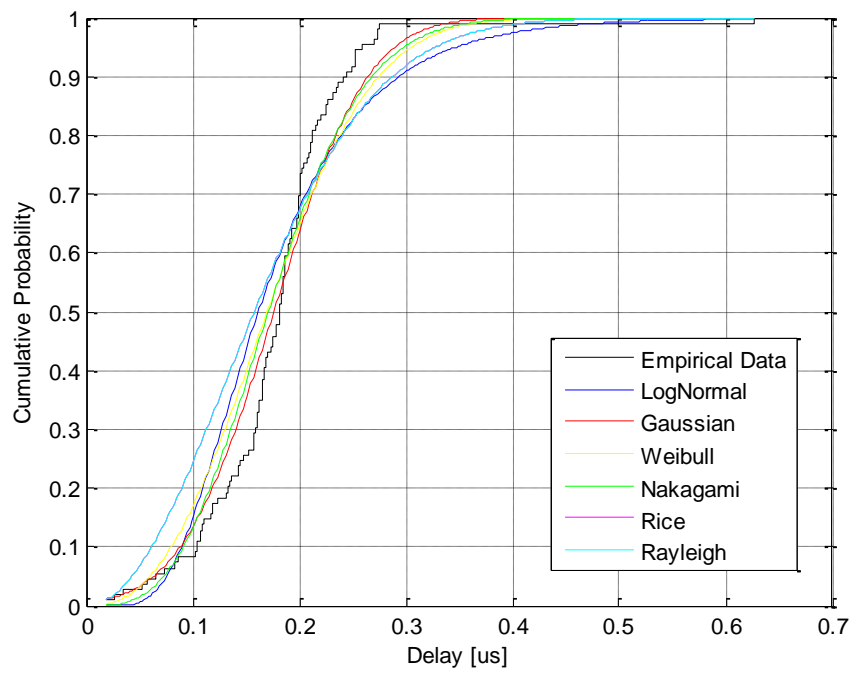

(c)

Fig. 15. Fitted Cumulative Distributions of RMS Delay Spread: (a) Rand, (b) PN (c) ZC 
Journal of Microwaves, Optoelectronics and Electromagnetic Applications, Vol. 18, No. 4, December 2019522 DOI: http://dx.doi.org/10.1590/2179-10742019v18i41704

TABLE IX. RMS DELAY SPREAD VALUES EXCEEDED FOR 50\% AND 95\% OF THE CASES

\begin{tabular}{|c|c|c|}
\hline Sequences & Percentage & RMS Delay $(\boldsymbol{\mu s})$ \\
\hline \multirow{2}{*}{ RAND } & $50 \%$ & 0.11 \\
\cline { 2 - 3 } & $95 \%$ & 0.25 \\
\hline \multirow{2}{*}{ PN } & $50 \%$ & 0.07 \\
\cline { 2 - 3 } & $95 \%$ & 0.21 \\
\hline \multirow{2}{*}{ ZC } & $50 \%$ & 0.18 \\
\cline { 2 - 3 } & $95 \%$ & 0.26 \\
\hline
\end{tabular}

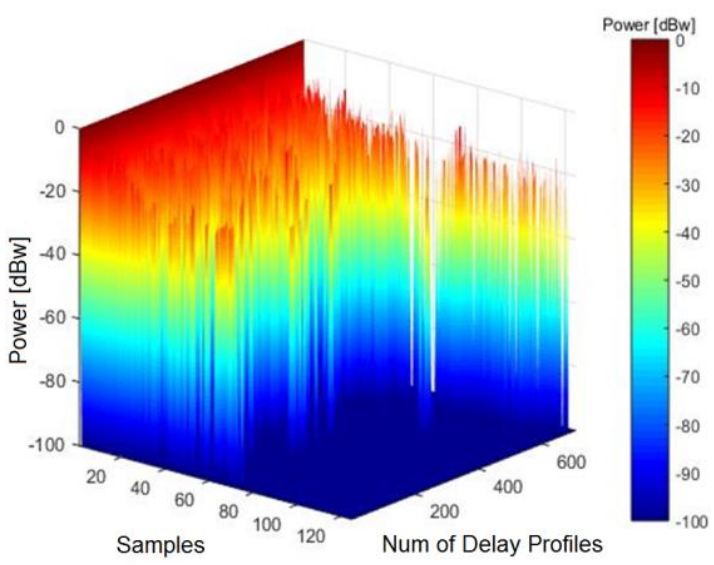

(a)

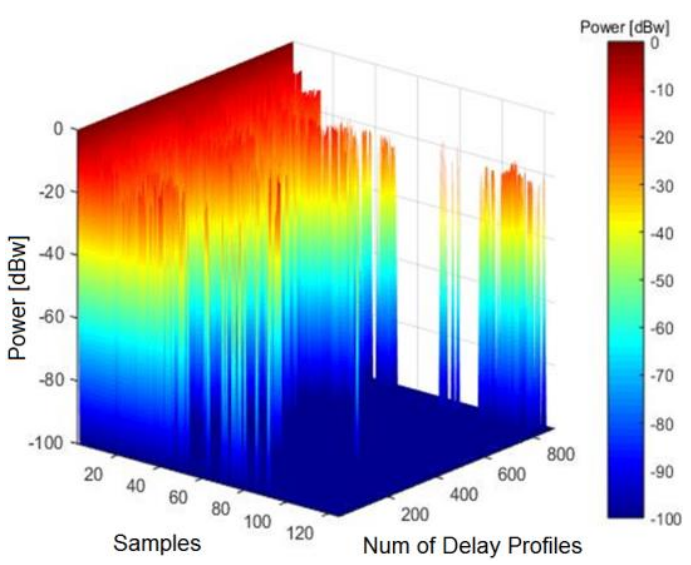

(b)

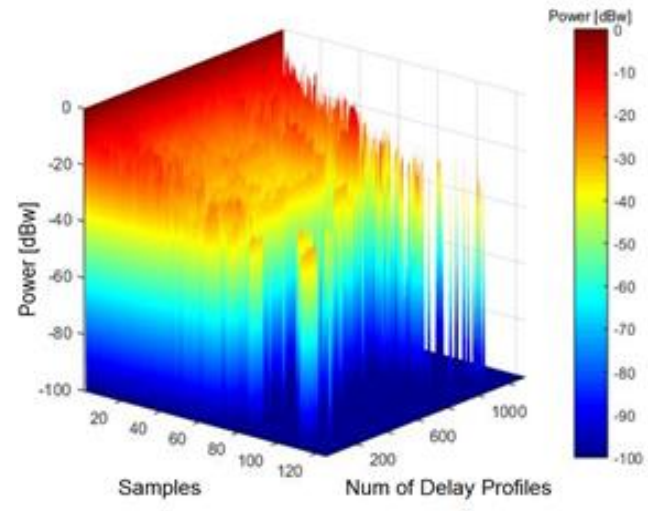

(c)

Fig. 16. Multipath Valid after applying the CFAR technique: (a) Rand, (b) PN and (c) ZC.

Table $\mathrm{X}$ shows the average value of the CFAR noise thresholds for each sequence. Fig 17 shows histograms of the thresholds obtained for all measured profiles with each sequence.

TABLE X. CFAR TECHNiQue Average THRESHOLD

\begin{tabular}{|c|c|c|c|}
\hline Sequences & RAND & PN & ZC \\
\hline Threshold dBW & $-27,3$ & $-25,1$ & $-37,2$ \\
\hline
\end{tabular}


Journal of Microwaves, Optoelectronics and Electromagnetic Applications, Vol. 18, No. 4, December 2019523 DOI: http://dx.doi.org/10.1590/2179-10742019v18i41704

It is possible to observe in table $\mathrm{X}$ that the $\mathrm{ZC}$ sequence has a lower of threshold level for the CFAR technique than the other two sequences. This is the reason why it is possible to identify more multipath components with the ZC sequence, as shown in Fig. 17.

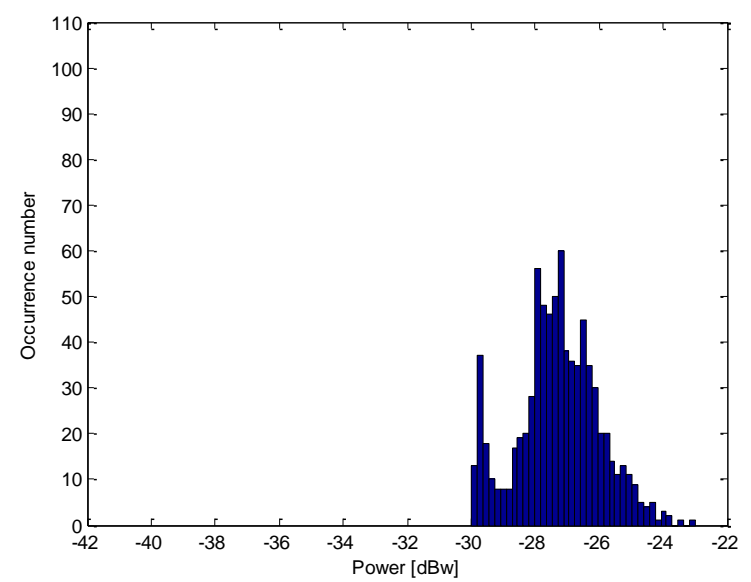

(a)

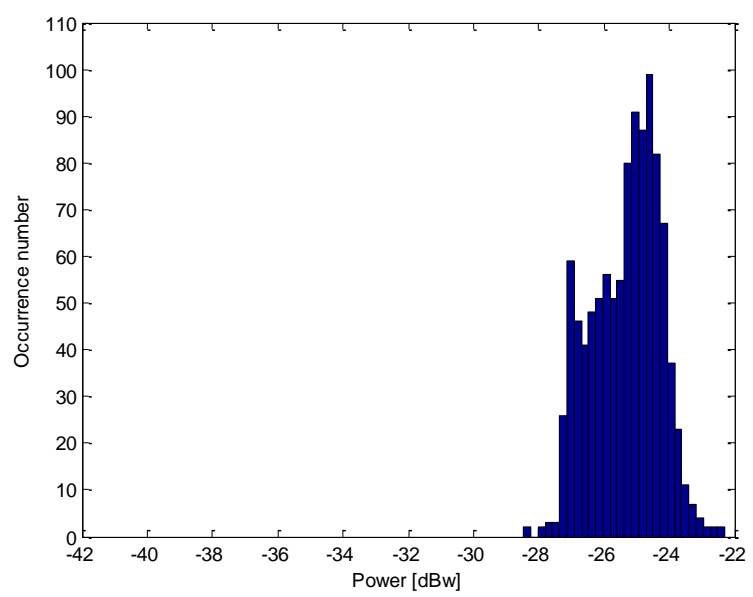

(b)

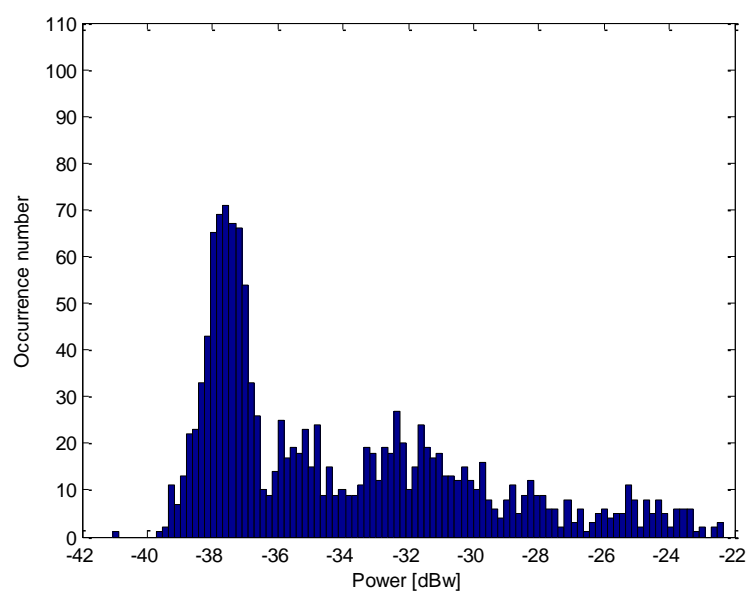

(c)

Fig. 17. Histograms of the thresholds obtained in the CFAR technique for each profile (a) Rand, (b) PN and (c) ZC. 
Journal of Microwaves, Optoelectronics and Electromagnetic Applications, Vol. 18, No. 4, December 2019524 DOI: http://dx.doi.org/10.1590/2179-10742019v18i41704

\section{Number of multipath components}

Fig 18 (a), (b) and (c) show the cumulative probability distributions of the number of multipath components measured with each type of test sequence and the fitting obtained with the Poisson distribution. Fig 18 (d) shows the comparison between the results with the three sequences. It can be seen that the ZC sequence allows to identify a much larger number of multipath components.

Fig 19 illustrates this effect, showing the delay profiles measured with each sequence at the same single measurement point. The RAND and PN sequences with a noise threshold between -25 and -30 $\mathrm{dBm}$ fail to identify multipaths detected by the $\mathrm{ZC}$ sequence, which has a noise threshold of approximately $-37 \mathrm{dBm}$.

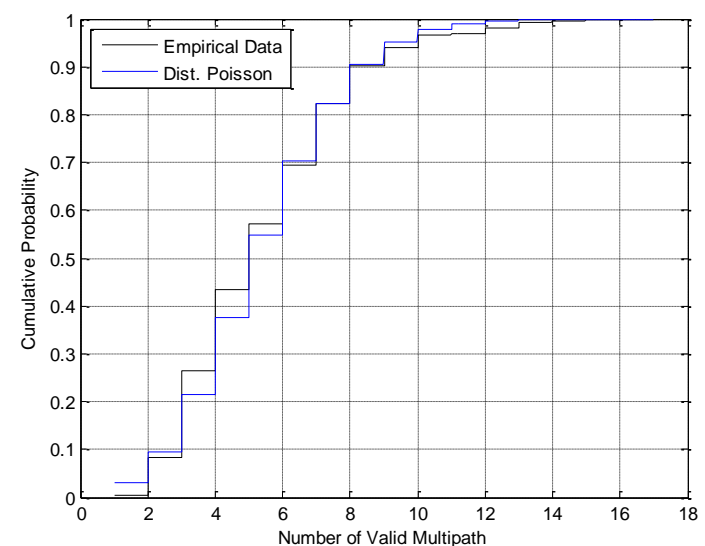

(a)

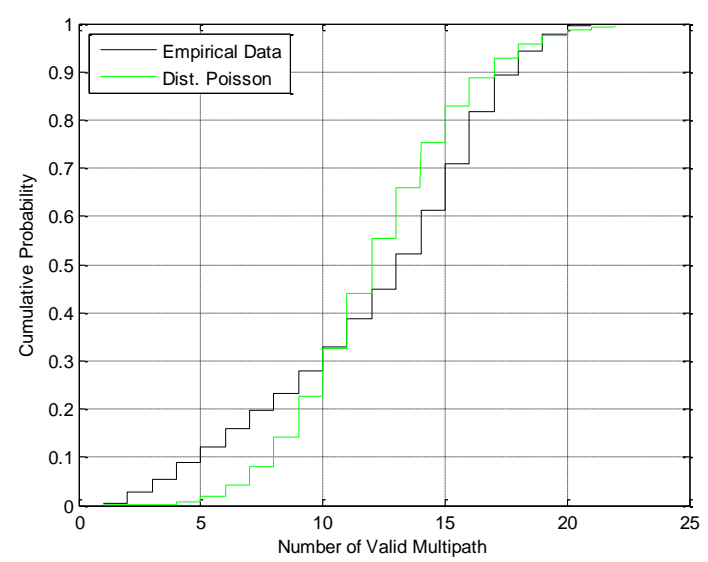

(c)

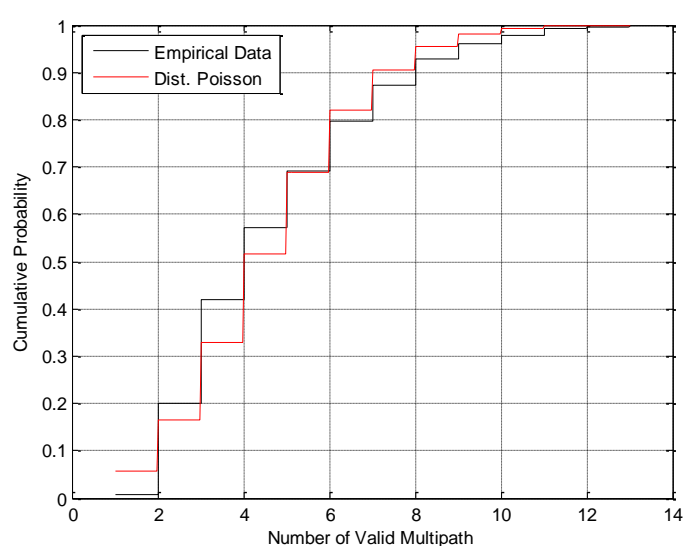

(b)

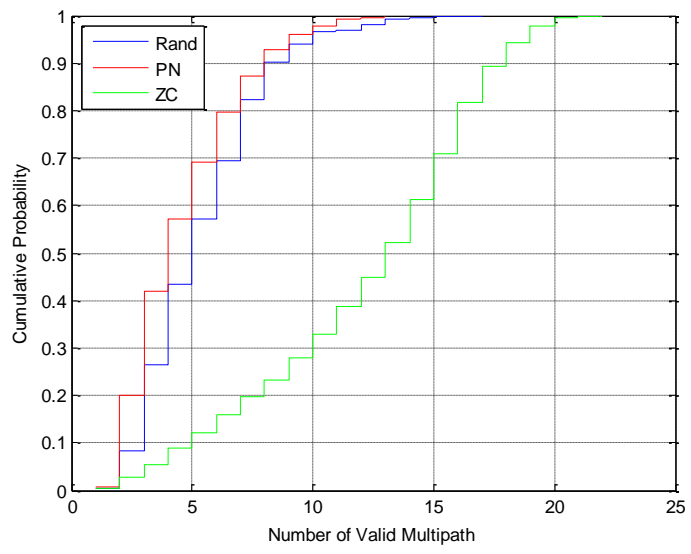

(d)

Fig. 18. Cumulative Distribution of the Number of Multipaths Components: (a) Rand, (b) PN (c) ZC and (d) Comparison of the three distributions. 


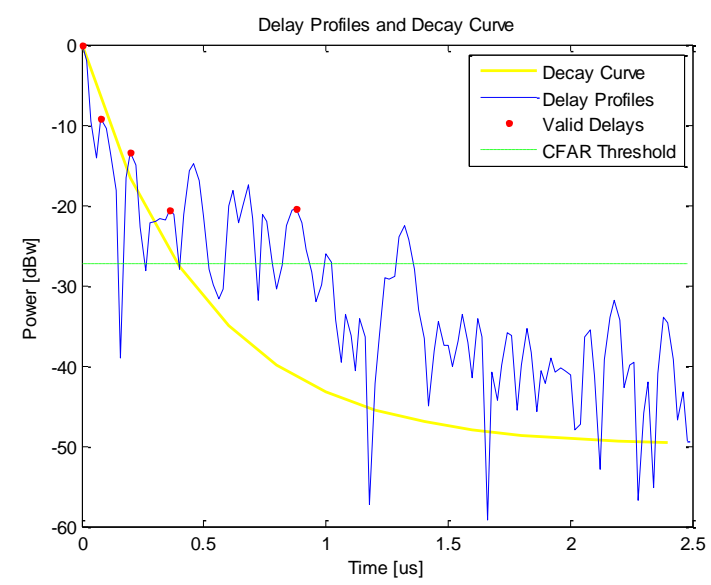

(a)

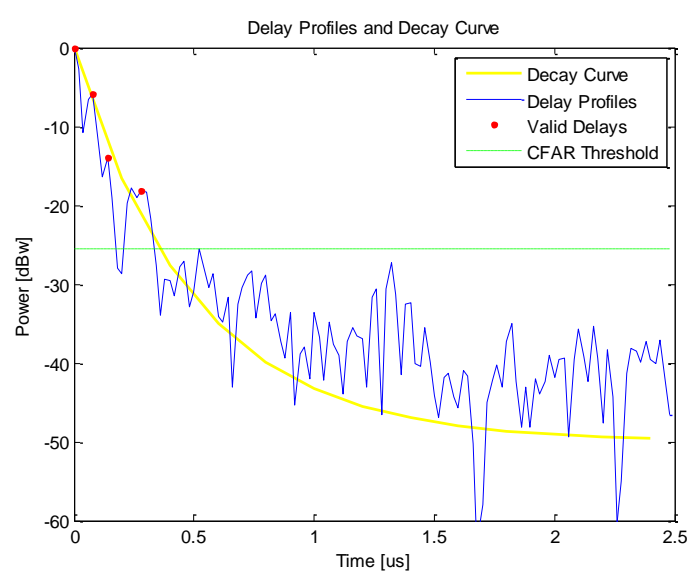

(b)

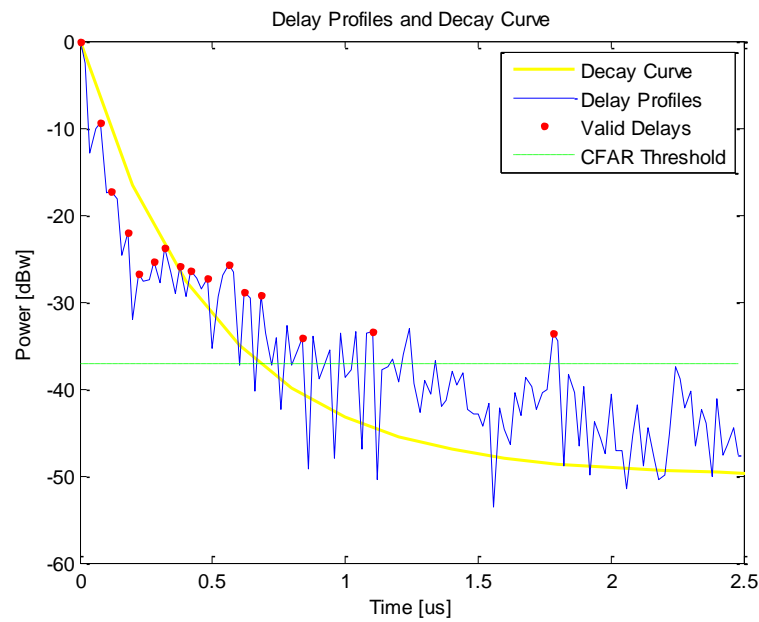

(c)

Fig. 19. Power delay profiles measured the same point using the three sequences: (a) Rand, (b) PN e (c) ZC.

\section{E. Amplitude of the components of multipath}

Fig 20 shows the cumulative distributions of the amplitudes of the measured multipath components and the adjustment with different theoretical probability distributions. The coefficients of the adjusted distributions and the adjustment errors are shown in Table XI.

Fig 20 (d) shows an interesting result, indicating that lower amplitude components are present in the detection of the $\mathrm{ZC}$ sequence. This is the consequence, again, of the lower noise threshold presented by the ZC sequence. This result is reflected in Table XII. 


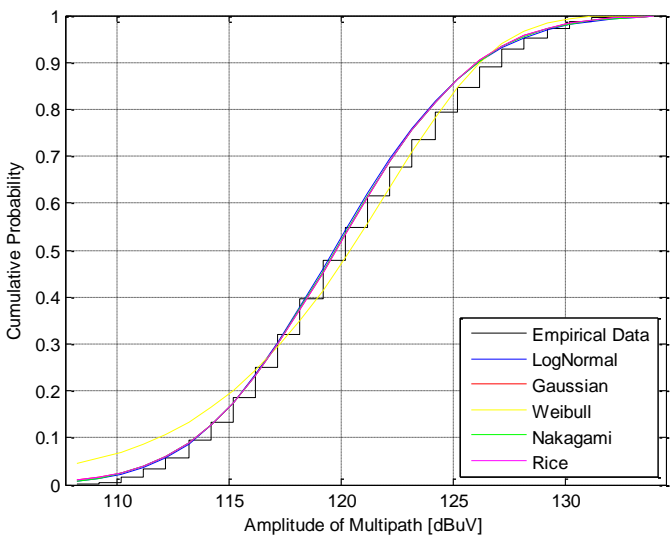

(a)

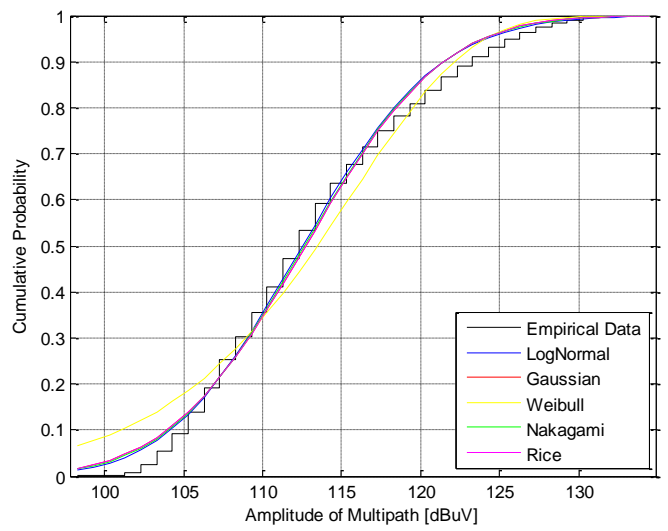

(c)

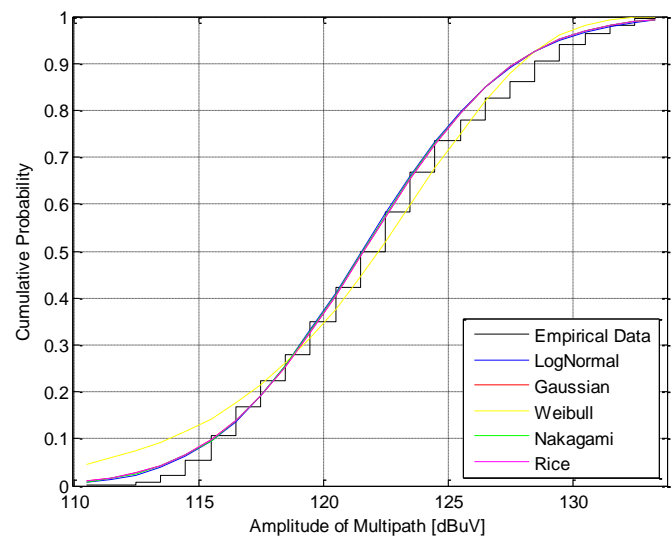

(b)

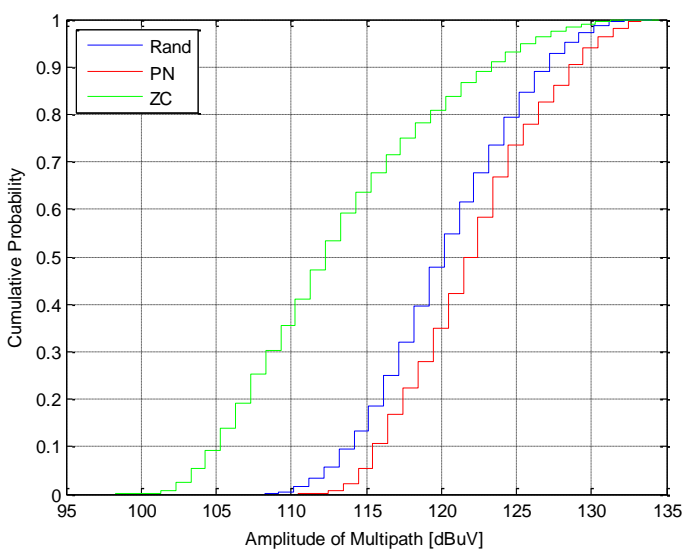

(d)

Fig. 20. Cumulative distribution of the amplitudes of the multipath components: (a) Rand, (b) PN, (c) ZC, (d) comparison.

TABLE XI. CUMULATIVE DISTRIBUTION PARAMETERS OF THE AMPLITUDES OF MULTIPATH

\begin{tabular}{|c|c|c|c|c|c|c|c|c|c|c|}
\hline \multirow{2}{*}{ RAND Sequence } & \multicolumn{2}{|c|}{ LogNormal } & \multicolumn{2}{|c|}{ Gaussian } & \multicolumn{2}{|c|}{ Weibull } & \multicolumn{2}{|c|}{ Nakagami } & \multicolumn{2}{|c|}{ Rice } \\
\hline & $\mu$ & $\sigma$ & $\mu$ & $\sigma$ & $\mu$ & $\sigma$ & $\mu$ & $\sigma$ & $\mu$ & $\sigma$ \\
\hline $\begin{array}{c}\text { MLE estimated } \\
\text { parameters }\end{array}$ & 4,79 & 0,04 & 119,77 & 4,91 & 122,15 & 25,48 & 149,00 & $14.370,00$ & 119,67 & 4,92 \\
\hline Mean of error & \multicolumn{2}{|c|}{$-0,0001$} & \multicolumn{2}{|c|}{$-0,0003$} & \multicolumn{2}{|c|}{0,0018} & \multicolumn{2}{|c|}{$-0,0002$} & \multicolumn{2}{|c|}{$-0,0003$} \\
\hline RMS error & \multicolumn{2}{|c|}{0,0115} & \multicolumn{2}{|c|}{0,0127} & \multicolumn{2}{|c|}{0,0347} & \multicolumn{2}{|c|}{0,0121} & \multicolumn{2}{|c|}{0,0127} \\
\hline \multirow{2}{*}{ PN Sequence } & \multicolumn{2}{|c|}{ LogNormal } & \multicolumn{2}{|c|}{ Gaussian } & \multicolumn{2}{|c|}{ Weibull } & \multicolumn{2}{|c|}{ Nakagami } & \multicolumn{2}{|c|}{ Rice } \\
\hline & $\mu$ & $\sigma$ & $\mu$ & $\sigma$ & $\mu$ & $\sigma$ & $\mu$ & $\sigma$ & $\mu$ & $\sigma$ \\
\hline $\begin{array}{c}\text { MLE estimated } \\
\text { parameters }\end{array}$ & 4,79 & 0,04 & 121,59 & 4,73 & 123,90 & 26,53 & 166,00 & 14807,00 & 121,49 & 4,73 \\
\hline Mean of error & \multicolumn{2}{|c|}{0,0001} & \multicolumn{2}{|c|}{$-0,0002$} & \multicolumn{2}{|c|}{0,0019} & \multicolumn{2}{|c|}{$-0,0001$} & \multicolumn{2}{|c|}{$-0,0002$} \\
\hline RMS error & \multicolumn{2}{|c|}{0,0162} & \multicolumn{2}{|c|}{0,0179} & \multicolumn{2}{|c|}{0,0417} & \multicolumn{2}{|c|}{0,0173} & \multicolumn{2}{|c|}{0,0179} \\
\hline \multirow{2}{*}{ ZC Sequence } & \multicolumn{2}{|c|}{ LogNormal } & \multicolumn{2}{|c|}{ Gaussian } & \multicolumn{2}{|c|}{ Weibull } & $\mathrm{Nal}$ & agami & Ric & \\
\hline & $\mu$ & $\sigma$ & $\mu$ & $\sigma$ & $\mu$ & $\sigma$ & $\mu$ & $\sigma$ & $\mu$ & $\sigma$ \\
\hline $\begin{array}{c}\text { MLE estimated } \\
\text { parameters }\end{array}$ & 4,72 & 0,06 & 112,71 & 6,82 & 116,04 & 16,28 & 69,00 & 12750,00 & 112,50 & 6,82 \\
\hline Mean of error & $-0,0$ & 004 & $-0,00$ & & $-0,0$ & 008 & & 0008 & $-0,00$ & \\
\hline RMS error & $\mathbf{0 , 0}$ & 248 & 0,02 & & 0,0 & & & 0277 & 0,02 & \\
\hline
\end{tabular}


TABLE XII. VALUES OF AMPLITUDES IN THE PERCENTAGE OF THE CASES INDICATED

\begin{tabular}{|c|c|c|}
\hline Sequences & Percentage & Amplitude $\mathbf{d B} \boldsymbol{\mu} \mathbf{V}$ \\
\hline \multirow{2}{*}{ RAND } & $50 \%$ & 120,2 \\
\cline { 2 - 3 } & $95 \%$ & 128,2 \\
\hline \multirow{2}{*}{ PN } & $50 \%$ & 122,5 \\
\cline { 2 - 3 } & $95 \%$ & 130,5 \\
\hline \multirow{2}{*}{ ZC } & $50 \%$ & 112,3 \\
\cline { 2 - 3 } & $95 \%$ & 126,3 \\
\hline
\end{tabular}

\section{CONCLUSIONS}

The objective of this work was to compare the results of the characterization of a broadband channel using the OFDM sounding technique with three different random modulating sequences (Rand, PN and ZC). First, computer simulations were performed with a synthesized deterministic channel to allow the evaluation of the three signals performance with exactly the same conditions.

The three sequences used to modulate the OFDM signal have shown very similar performance in the simulations, considering the three metrics used in the evaluation. The $\mathrm{ZC}$ sequence presented sligthly smaller sounding errors and fluctuations, and a smaller peak to average power ration. These results are in accordance with [14], that first proposed the use of this ZC sequence for broadband channel sounding. The differences, however, are not enough to indicate definite advantages of the use a particular sequence.

In the field measurements, on the other hand, the $\mathrm{ZC}$ sequence has shown a very significant advantage over the other two sequences. That is due to the fact that, as the channel is randomly time variant, it is necessary to apply a filtering technique to avoid that undesired spurious be falsely interpreted as multipath components. The main advantage of the ZC sequence is that it presents significantly lower CFAR noise thresholds, about $10 \mathrm{~dB}$ below those of the RAND and PN sequences, thus allowing the identification of multipath components that are not detected with the other sequences. On the other hand, the use of the ZC sequence limited the sounding, in our case, to a $2.5 \mu \mathrm{s}$ time window as the sequence itself shows correlation peaks outside this range. Each peak generates a replica of the channel and in the data processing these replicas could be interpreted by multipath clusters [19].

The conclusion is that the $\mathrm{ZC}$ sequence is the most adequate and sound channels characterized by relatively short delay spreads, as channels in dense urban environments, vehicle-to-vehicle channels and indoor channels. These are, however, very relevant types of channels for $5 \mathrm{G}$ networks.

The average values of the RMS delay spread obtained were $0.13 \mu$ s using the Rand sequence, 0.082 $\mu$ s with the PN sequence and $0.18 \mu$ s with the $\mathrm{ZC}$ sequence. This is due to the fact that the $\mathrm{ZC}$ sequence, with a lower CFAR noise threshold, allows the identification of several multipath 
components that are missed in the sounding with the other sequences. The ability to properly characterize a higher value of RMS delay spread value is particularly important, as the coherence bandwidth of the channel is inversely proportional to this parameter.

The cumulative distributions of RMS delay spread were best fitted by different distributions depending on the sounding sequence used. For the Rand sequence, the best fit was the Rayleigh distribution, whereas the PN sequence produced results best fitted by a lognormal distribution and the ZC sequence by a Gaussian distribution. The differences between the distributions were not, however, very significant.

The cumulative distributions of the number of multipath components was fitted well to a Poisson distribution in all three cases. Similarly, the cumulative distributions of the amplitudes of the multipath components presented a best fit with the distribution lognormal in all three cases.

\section{REFERENCES}

[1] J. D. Parsons, D. A. Demery and A. M. D. Turkmanil, "Sounding techniques for wideband mobile radio channels: a review," IEEE Processing communication, speech and vision, vol. 138, no. 5, pp. 437-446, 1991.

[2] Theodore S. Rappaport, "Wireless Communications: Principles and Practice - Theodore Rappaport" Second Edition, published 2011.

[3] T. S. Rappaport, "Characterization of UHF Radio Channels in Factory Buildings," IEEE Transactions on Antennas and Propagation, vol. 37, pp. 1058-1069, 1989.

[4] D. Cox, "Delay Doppler characteristics of multipath propagation at $910 \mathrm{MHz}$ in a suburban mobile radio environment," IEEE Transactions on Antennas and Propagation, vol. 20, no. 5, pp. 625-635, Jan. 1972.

[5] R. M. L. Silva, G. L. Siqueira, L. H. Gonsioroski, C. R. V. Ron, "Comparison between OFDM and STDCC mobile channel sounders at $3.5 \mathrm{GHz}$, , Journal of Microwaves, Optoelectronics and Electromagnetic Applications, vol. 12, no. 1, pp. 1-14, 2013.

[6] G. Acosta-Marum, "Measurements, Modeling, and OFDM Synchronization for the Wideband Mobile-to-Mobile Channel", PhD Thesis, Georgia Institute of Technology, 2007.

[7] L. Wei and C. Schlegel, "Synchronization requirements for multi-user OFDM on satellite mobile and two-path Rayleigh fading channels," IEEE Trans. Commun., vol. 43, pp. 887-895, 1995.

[8] S. Dixit and H. Katiyar, "Performance of OFDM in time selective Multipath fading channel in 4G Systems," Fifth International Conference on Communication Systems and Network Technologies, 2015.

[9] J. A. C. Bingham, "Multicarrier modulation for data transmission: An idea whose time has come," IEEE Commun. Mag., vol. 28, no. 5, pp. 5-14, 1990.

[10] H. Rohling, "OFDM Concepts for Future Communication Systems". Signals and Communication Technology, Institut für Nachrichtentechnik, Technische Universität Hamburg-Harbur, Springer-Verlag Berlin Heidelberg 2011.

[11] F. J. MacWilliams and N. J. Sloane, "Pseudo Random Sequences and Arrays," Proc. IEEE, vol. 64, no. 12, pp 17151730, December 1976.

[12] A. Mitra, "On the Properties of Pseudo Noise Sequences with a Simple Proposal of Randomness Test," World Academy of Science, Engineering and Technology International Journal of Electrical, Computer, Energetic, Electronic and Communication Engineering, vol. 2, no. 9, 2008.

[13] M. Hua, K. W. Yang, M. Wang, K. J. Zou, “Analysis of the Frequency Offset Effect on Zadoff-Chu Sequence Timing Performance," IEEE Transactions on Communications, vol. 62, no. 11, pp. 4024-4039, 2014.

[14] M. M. U. Gul, X. Ma, "Timing and Frequency Synchronization for OFDM Downlink Transmissions Using ZadoffChu Sequences," IEEE transactions on Wireless Communications, vol. 14, no. 3, pp. 1716-1729, March 2015.

[15] M. M. U. Gul, "Robust synchronization for OFDM employing Zadoff-Chu sequence," 2012 46th Annual Conference on Information Sciences and Systems (CISS).

[16] H. Rohling, "Radar CFAR Thresholding in Clutter and Multiple Target Situations," IEEE Transactions on Aerospace and Electronic Systems, vol. AES-19, no. 4, pp. 608-621, July 1983.

[17] J. El-Ghoul, K. R. Nanji, M. El-Tarhuni, and M. Barkat, "Experimental Implementation of Adaptive CFAR Multipath Detection for Wideband Communication Systems," The 18th Annual IEEE. Indoor and Mobile Radio Communications, July 2007.

[18] A. A. M. Saleh and R. A. Valenzuela “A Statistical Model for Indoor Multipath Propagation,” IEEE Journal on selected areas in communication, vol. 5, no. 2, pp. 128-137, February 1987.

[19] F. Vatalaro and A. Forcella, "Doppler spectrum in mobile-to-mobile communications in the presence of threedimensional multipath scattering”, IEEE Transactions on Vehicular Technology, vol. 46, no. 1, pp. 213-219, February 1997. 
Journal of Microwaves, Optoelectronics and Electromagnetic Applications, Vol. 18, No. 4, December 2019529 DOI: http://dx.doi.org/10.1590/2179-10742019v18i41704

[20] R. H. Clarke, “A Statistical Theory of Mobile Radio Reception,” The Bell System Technical Journal, vol. 47, no. 6, pp. 957-1000, July-Aug. 1968.

[21] Y. A. Jawhar, L. Audah, M. A. Taher, K. N. Ramli, N. S. M. Shah, M. Musa and M. S. Ahmed "A Review of Partial Transmit Sequence for PAPR Reduction in the OFDM Systems, "IEEE Access, vol. 7, pp. 18021-18041, 2019

[22] U. I. Butt "A Study on the Tone-Reservation Technique for Peak-to-Average Power Ratio Reduction in OFDM Systems," Florida USA 2010. 